\title{
فن التجميع وعلاقته بالوسائط التشكيلية لبقايا الزجاج في اثراء المشغولة المعدنية
}

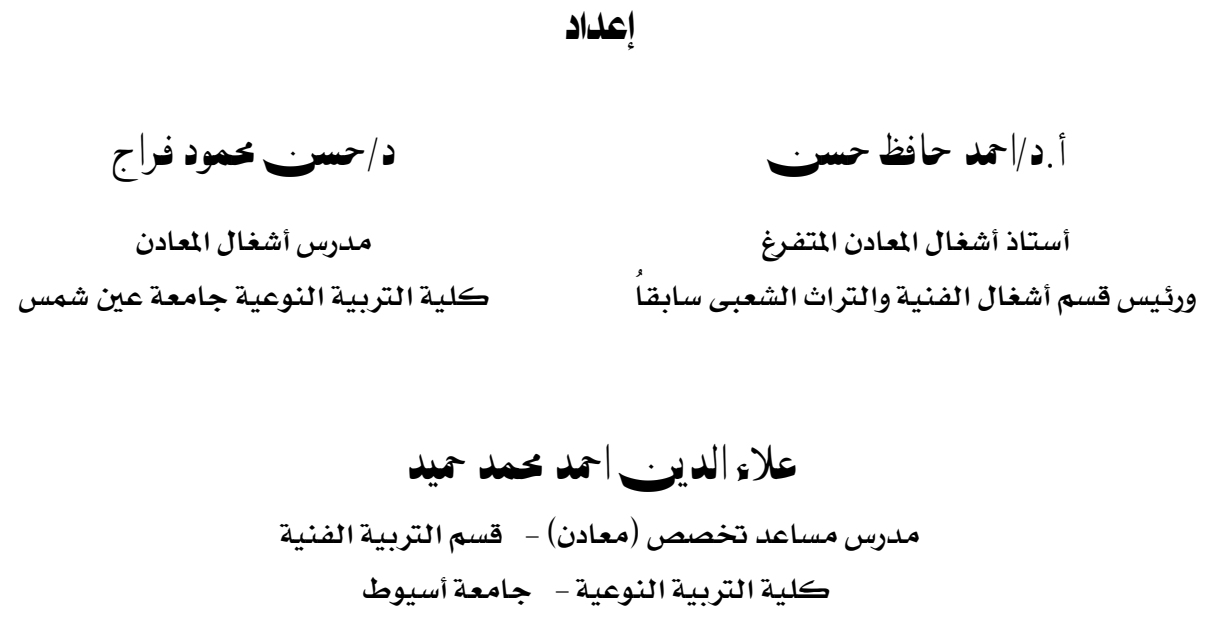

مجلة بحوث التربية النوعية - جامعة المنصورة

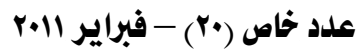




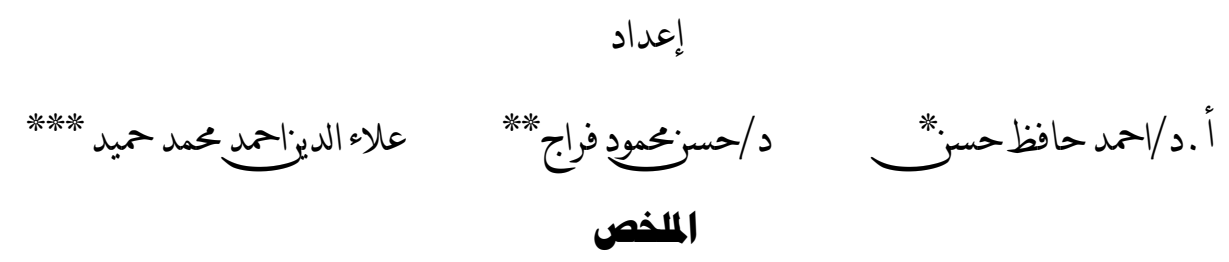

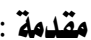

القرن العشرين اتسهم بالتقدم العلمي والتكنولوجي علي أوجه النشاط الفني مـا صـاحبة مـن

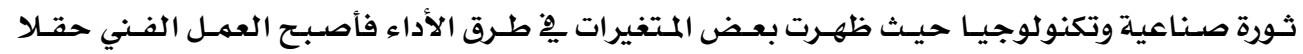

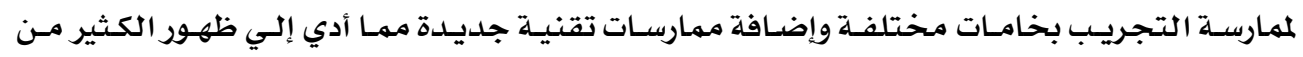

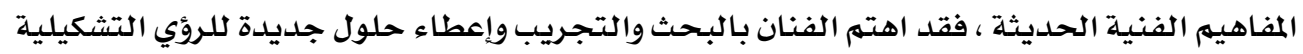

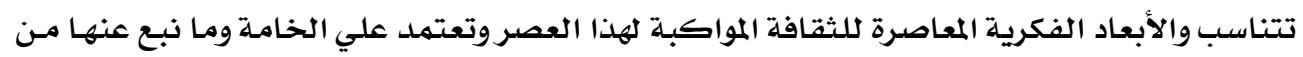

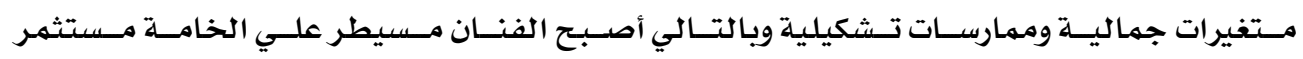

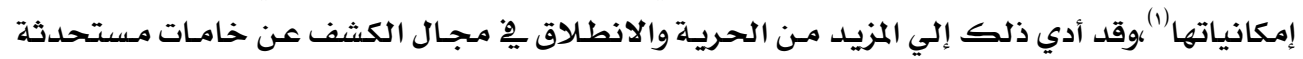

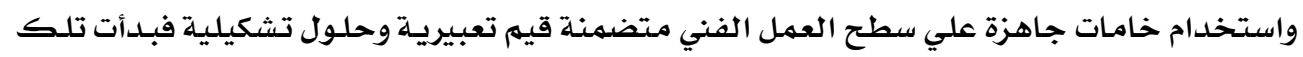

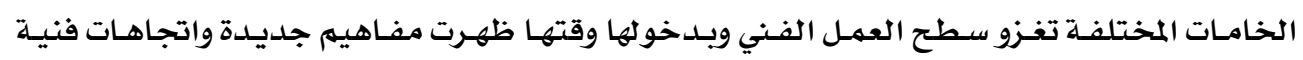

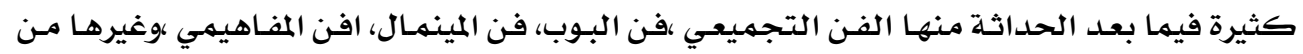

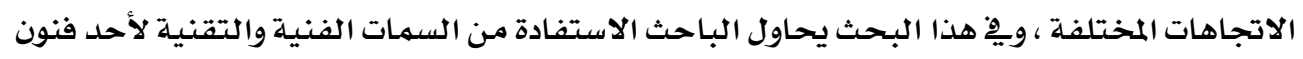

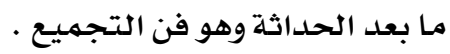
مشكلة البحث: كيف يهكن اسـتحداث تشكيلات معدنيـة معاصـرة ذات إمكانيـات تشكيلية بمعالجـات فنيـة لبقايا الزجاج مستوحاة من الفن التجميعى ل فرض البحث : - هناك علاقة ايجابية بين تقنيات ومعالجات بقايا الزجاج وبين إثراء التشكيلات المعدنيـة مستوحاة

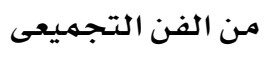

* أستاذ أشغال المعادن المتفرغ ورئيس قسم أشغال الفنية والتراث الشعبى سابقاُ

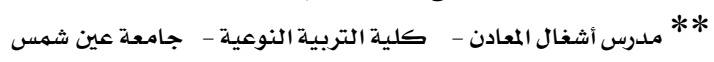

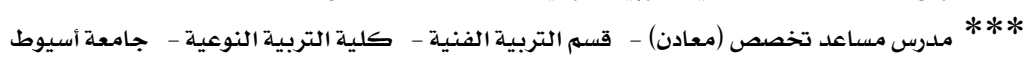

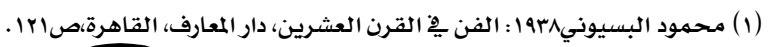


- طرح مداخل لتوظيف الزجاج والمعدن يِّ صياغات مستحدثة قائمة علي فن التجميع - التعرف علي أهم المعالجات التشكيلية والملامـح الفنية والوظيفية لهذه الأعمال.

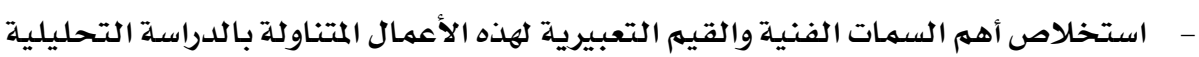

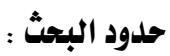

دراسة فن التجميع لبقايا الزجاج وعلاقتهم بالمشغولة المعدنية منهج البحث :

$$
\text { وصفي تحليلي }
$$

النتائج والتوصيات:

\section{من الدراسة كانت النتيجة:}

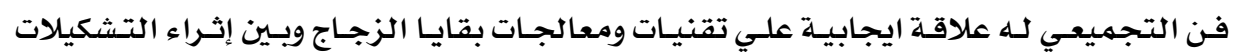

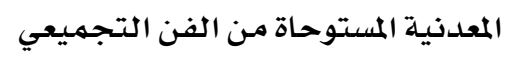

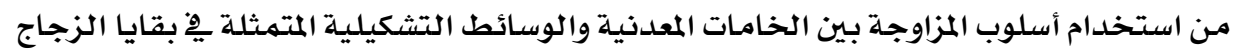

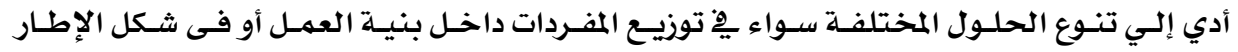

$$
\text { ولذارج يوصى الباحث للعمل الفني ككل وذلك مما عرض. }
$$

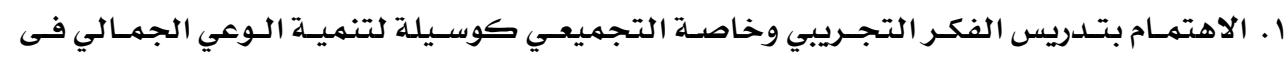

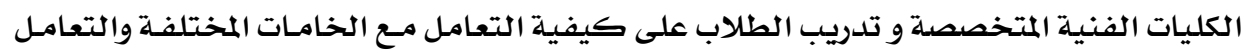

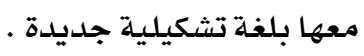

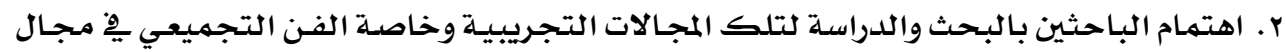

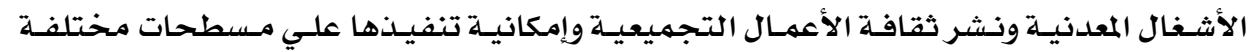

بخامات مناسبة. 


\section{ART OF ASSEMBLY AND ITS RELATIONSHIP TO MEDIA ARTS FOR THE REMNANTS OF GLASS TO ENRICH THE OCCUPIED METAL}

\section{Introduction:}

The twentieth century was characterized by the progress of scientific and technological aspects of artistic activity as author of the industrial revolution and technology where there have been some changes in the ways of performance, bringing the artwork field for the exercise of testing raw materials, different and add the practices of a new technique, which led to the emergence of many of the concepts of modern art, the artist took interest in research and experimentation and to give new solutions to felt fine commensurate with the dimensions of contemporary intellectual culture escort to this day and age, depend on raw material and spring by the variables of aesthetic and practice of plastic and thus became the artist in control of the raw investor potential (), has led to more freedom and starting in the detection of raw materials updated and the use of materials ready on the surface of the artwork, including values expressive and solutions Fine began with these materials different invade the surface of the artwork and entry and then emerged new concepts and trends of many technical with postmodernism, including art synthesis, pop art, art Alimmal, Waffen conceptual, and other different directions, and in this Find a researcher is trying to take advantage of the technical features and technical support for a post-modern art is the art of the assembly.

\section{Research problem:}

How can the development of formations of contemporary metal, plastic processors, the possibilities of art glass inspired by the remnants of the art synthesis.

\section{The imposition of Search:}

-There is a positive relationship between the techniques and processors remains between the glass and metal enrichment profiles of art inspired by the aggregate

\section{Research Objectives:}

- Put the entrances for the recruitment of glass and metal in the novel formulations based on the art of assembly

- Identify the most important processors of plastic and technical and functional features of these acts. 
- Extract the most important features of technical and expressive values of this work dealt with the analytical study

\section{Search limits:}

A Study of the art collection of the remains of glass and their relationship to mineral Palmchgolp

\section{Research Methodology:}

a descriptive and analytical

\section{Results and recommendations:}

The result of the study:

- The Art of the composite has a positive relationship on the techniques and processors remains between the glass and metal enrichment of formations inspired by the art synthesis

- Use a method of pairing between the mineral and media arts in the remnants of glass led to a variety of different solutions, both in the distribution of words within the structure of work or in the form of the outer frame of the work as a whole by putting.

\section{- Accordingly, it is recommended by:}

1 - interest in teaching empirical thought, especially the synthesis as a means for the development of aesthetic awareness in colleges and specialized technical training students on how to deal with various materials and dealing with a new plastic language.

2 - the attention of researchers to research and study to those areas particularly experimental and art works in the field of composite metal and dissemination of aggregate business culture and can be implemented on different surfaces suitable raw materials. 


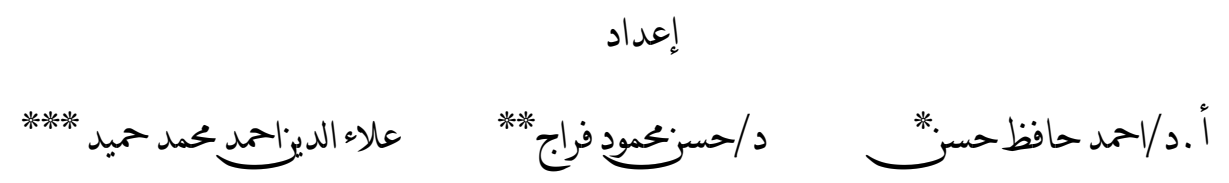

همدهة

القرن العشرين اتسهم بالتقدم العلمي والتكنولوجي علي أوجه النشاط الفني مـا صـاحبة مـن

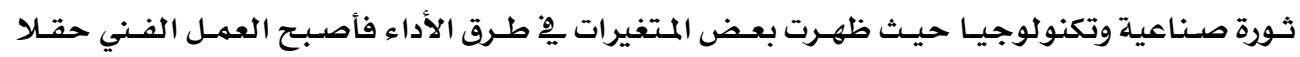

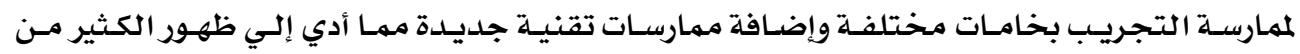

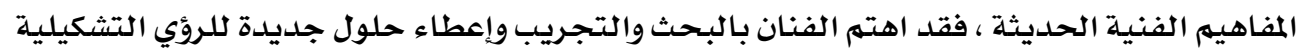

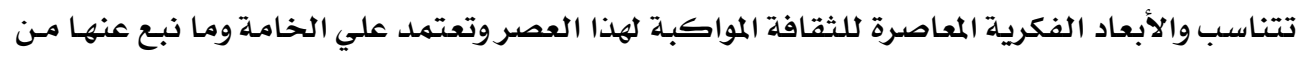

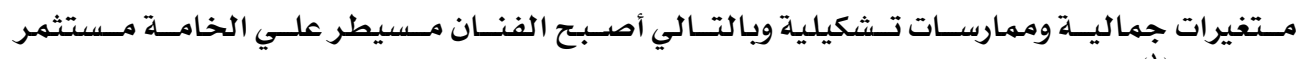

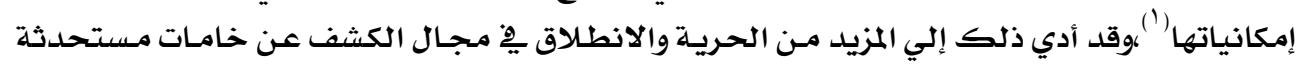

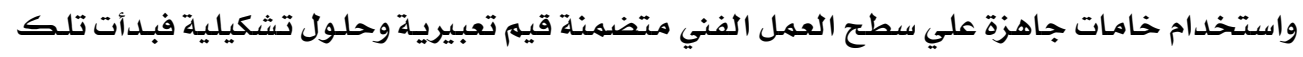

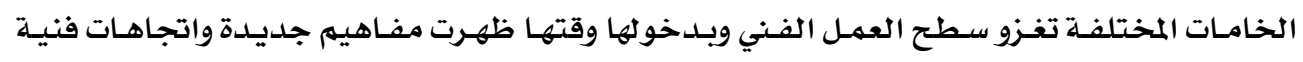

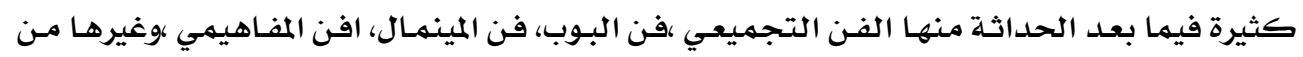

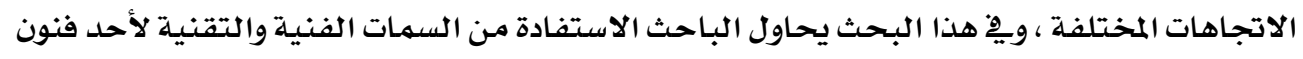

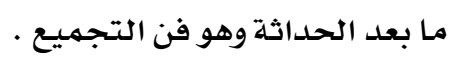

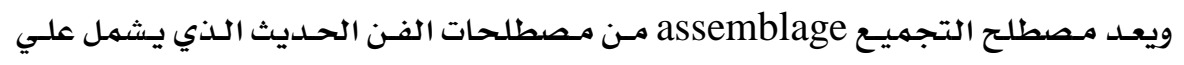

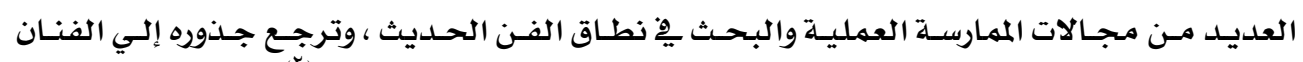

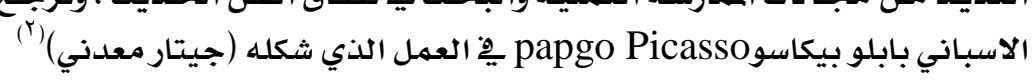

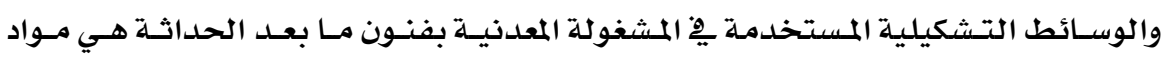

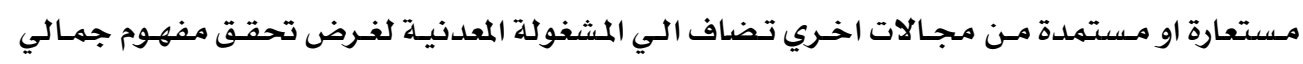

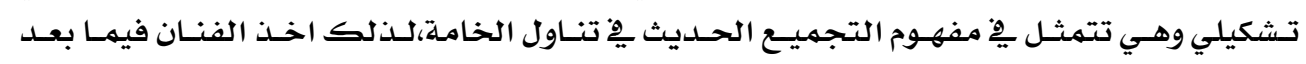

• أستاذ أشغال المعادن المتفرغ ورئيس قسهم أشغال الفنية والتراث الشعبى سابقاُ

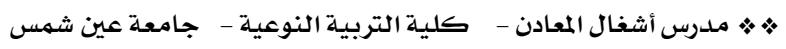

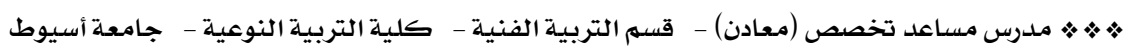

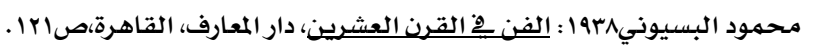

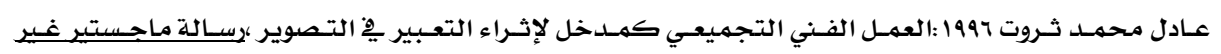


الحداثة يبحث عن الوسائط التشكيلية التي تتناسب واثراء المشغولة المعدنيـة فتنوعت الخامسة الملونـة

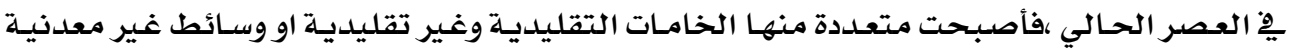

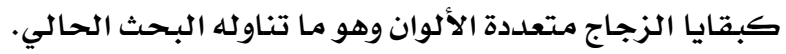

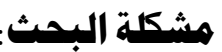

كيف يمكن اسـتحداث تشكيلات معدنيـة معاصـرة ذات إمكانيـات تشكيلية بهعالجـات فنيـة

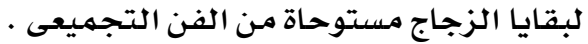

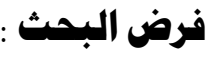
- - هناك علاقة ايجابية بين تقنيات ومعالجات بقايا الزجاج وبين إثراء التشكيلات المعدنيـة مستوحاة

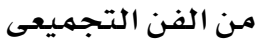

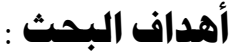

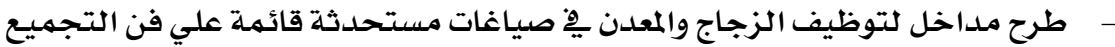

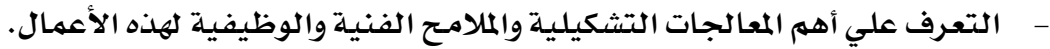

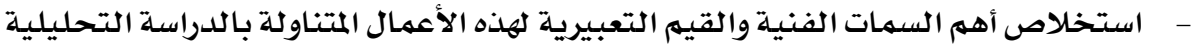
هدود البحث : دراسة فن التجميع لبقايا الزجاج وعلاقتهمه بالمثغولة المعدنية هنهج البحث :وصفي تحليلي الدراستة:

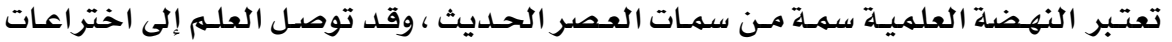

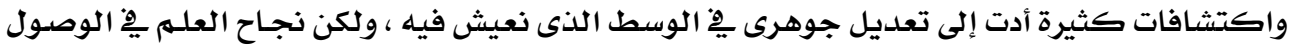

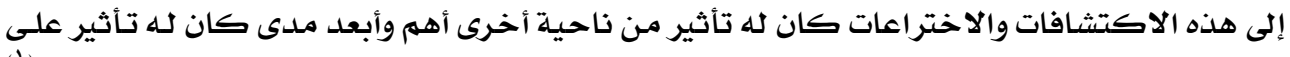

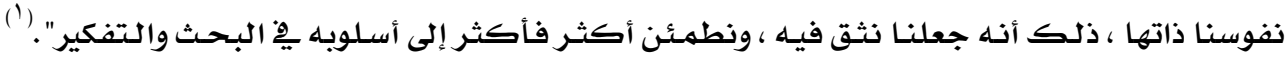

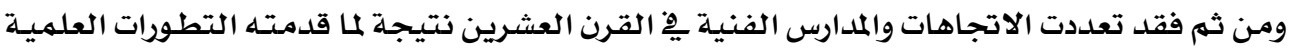
المعاصرة إلى رؤية الفنان.

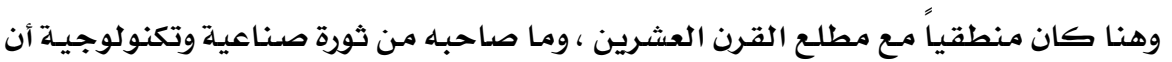

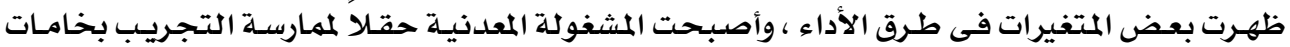

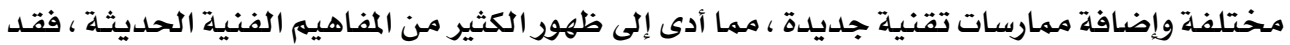

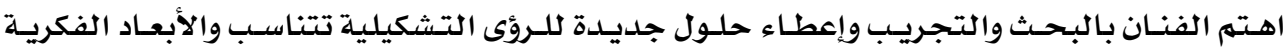

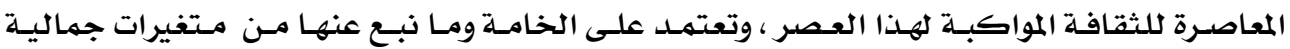

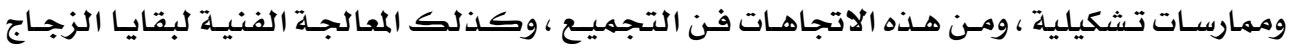

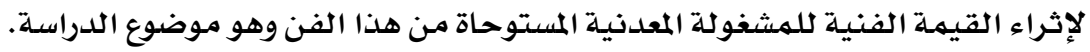

(1)- رمسيس يونان 1979 : دراسات في الفن ، المؤسسة المصرية العامة للكتاب والنشر ، القاهرة ، ص17 


\section{مفوم التجميع Assemblage}

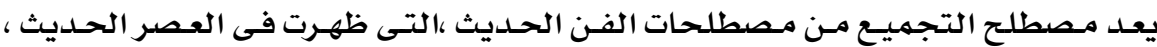

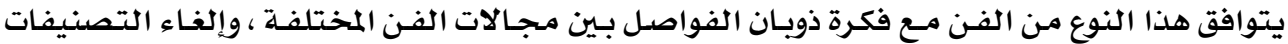

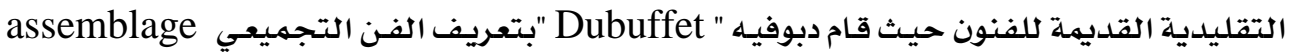

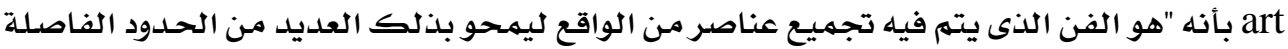

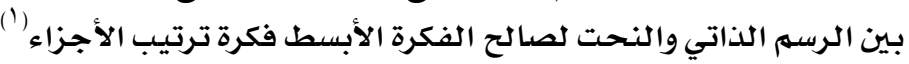

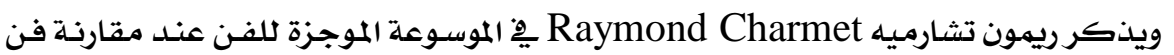

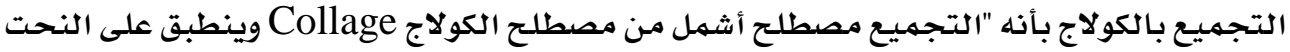

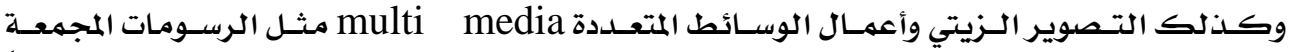

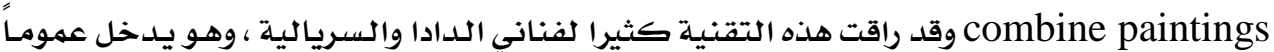

مِّف

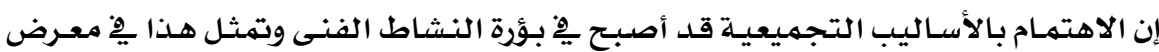

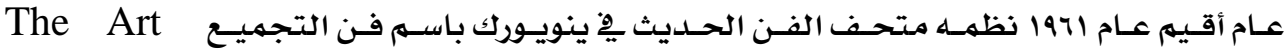

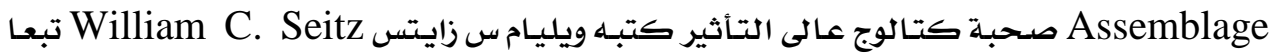

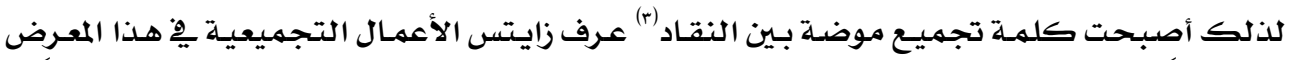

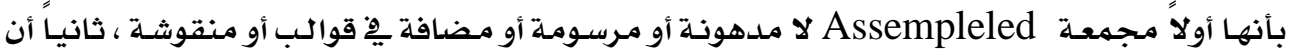

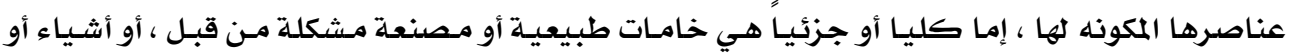

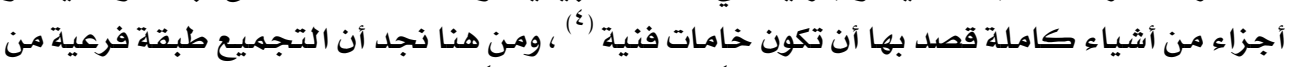

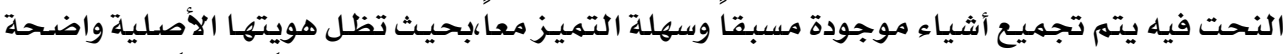

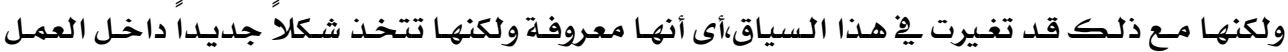

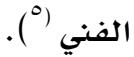

ومعنى (العمل الفن التجميعى) فى قاموس الفنون الجميلـة "أنـه تقنيـة بنـاء أعمال ثلاثيـة

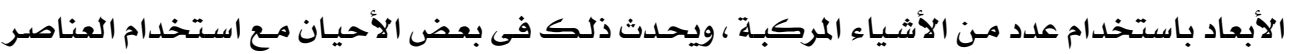

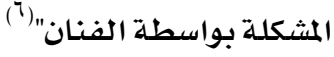

( ${ }^{1}$ )- Richard leslie : 1997, pop art anew Generation of style todri, new York p.44

(2)Raymond Charmet : 1972, concise Encyclopedia of Modern Art Collins Glasgow, London, p.15 -

Edward Lucie - Smith: 1987, Sculpture Since. 1945, phaidon, London, p. $50-\left({ }^{3}\right)$

$\left({ }^{4}\right)$ - H.H. Arnasoi : 1975 , A history of Modern Art Painting . Sculpture. Architectur, Thames and Hudson, p. 603

(1) Duane and Sarah Preble : 1985 Art forms Harper and Row publishers new York p. 173.

$\left({ }^{6}\right)$ Robert Atkins 1990 : Art Speak" Abbeville Ruess, New York, P. 110. 
العوامل التى أدت إلى ظهور فن التجميع فى الفن المعاصر :

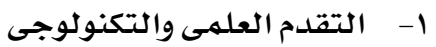

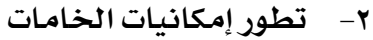

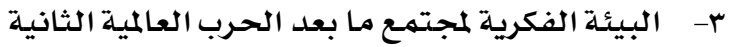

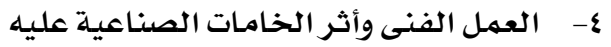

أهم الاتجاهات الفنية الحديثة التى تناولت أسلوب التجميع :

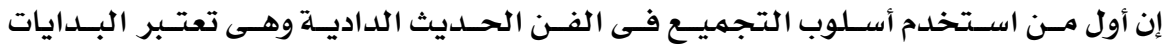

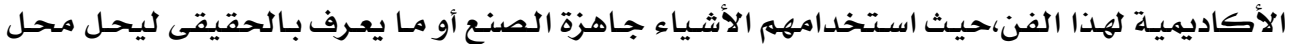

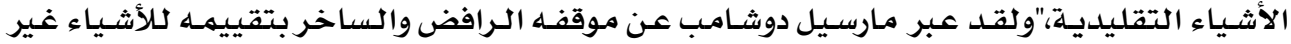

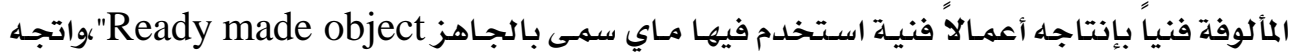

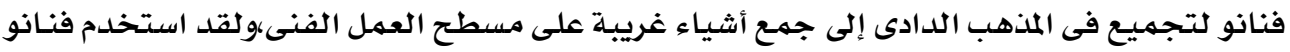

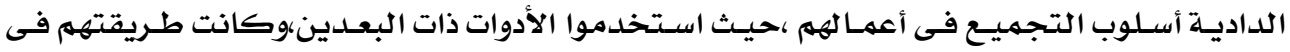

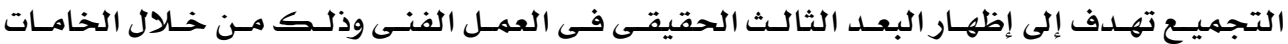
جاهزة الصنـع.

\section{الدادية : وفلسفة التجميع فى المذاهب الدادى :}

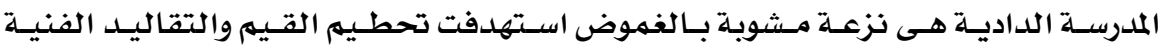

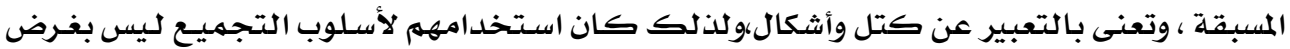

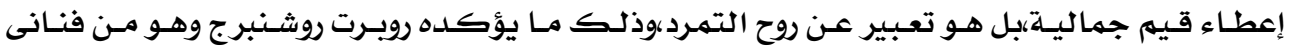

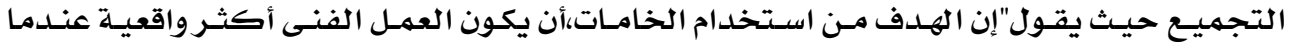

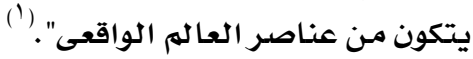

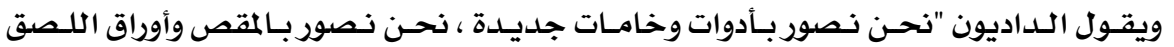

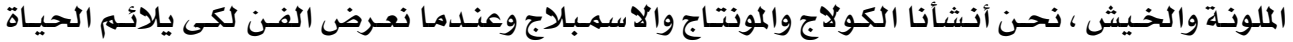

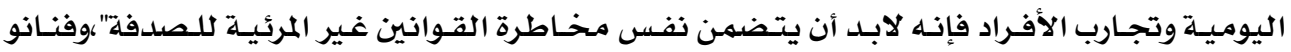

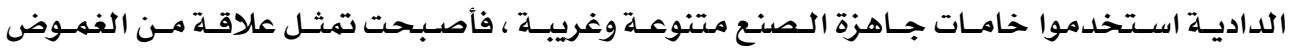

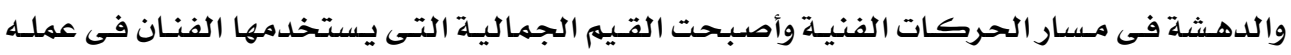

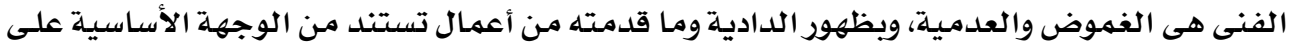

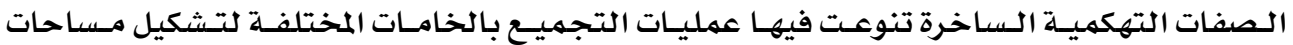

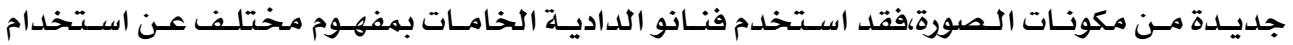

(') جوهانز أيتين 1991 : التصميسمواشكل في مدرسـة البلوهـاوس ، ترجمـة / صبرى عبد الغنى ، المجلس الأعلى للثقافة ، 
التكعيبيين،فاستخدامهم للخامات كان أساسـ التمرد ليس ضـد الشكل،ولكن ضـد الأفكار التقليديـة

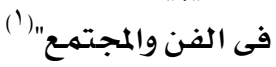

توظيف المدذب الدادى للتجميع : استخدام فنانو الدادية أسلوب التجميع في أعما لهم وهـو



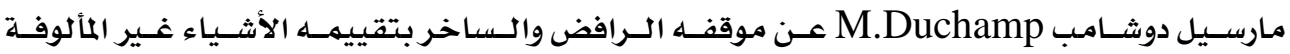

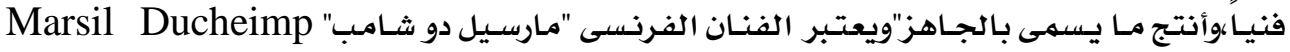

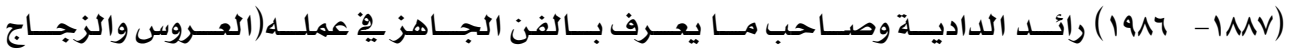

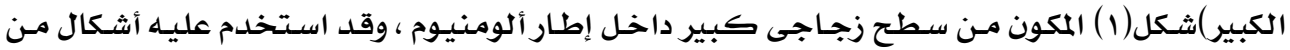

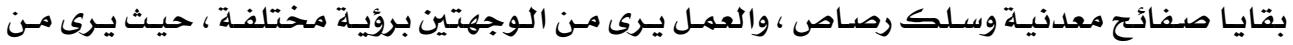

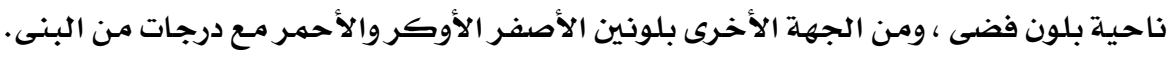

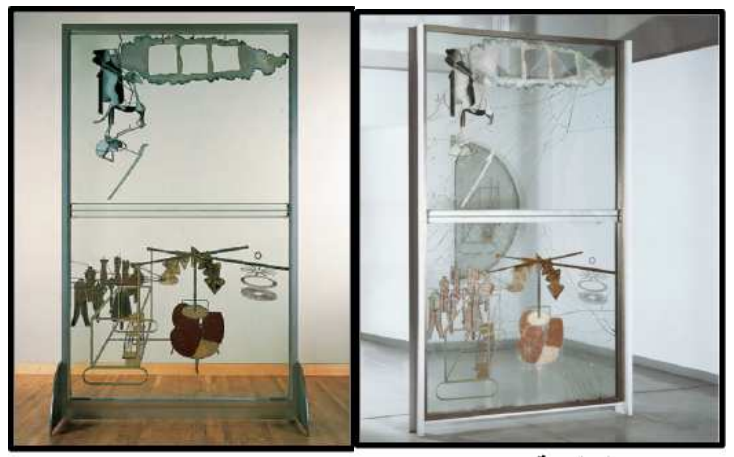

شكل رقم(1)

التكميبية:وفلسفة التجميع في المذهب التكميبي : إن فن التجميع Assemblage Art مثل كل الفنـون البصرية جـذوره عميقة يِّ الماضى ،

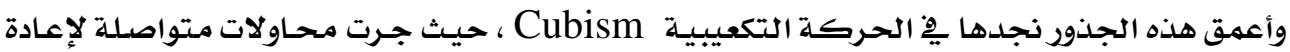

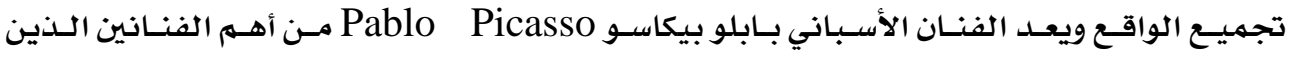

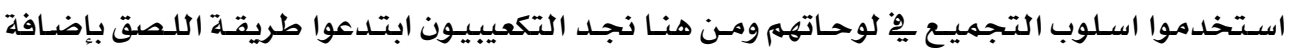

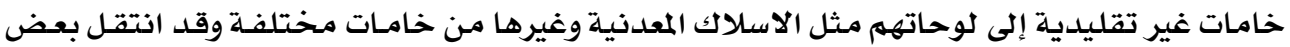

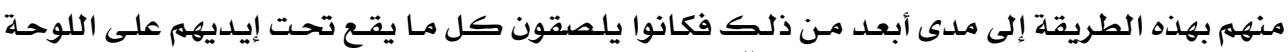

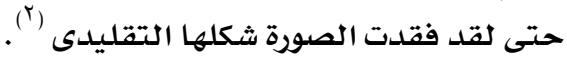
(†) محمد رضـا عبد السلام ז1919 : اللون واستخدامـه فى التصوير الحديث ، رسـالة مـاجستير غير منشورة، كلية الفنون

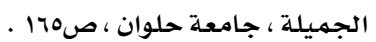
(') جورج فلانجان باه1 : حول الفن الحديث، ترجمة ، كمال الملاخ ، صلاح طاهر ، دار المعارف ، القاهرة ، ص سجr . 
توظيف المدهب التكعيبي للتجميع : استخلدم فنـانوا المـذهب التكعيبي تقنيـات استخلدام

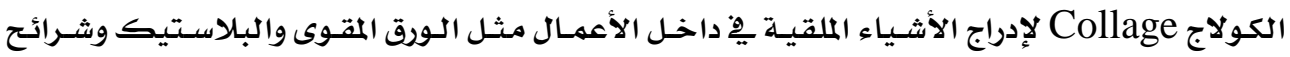

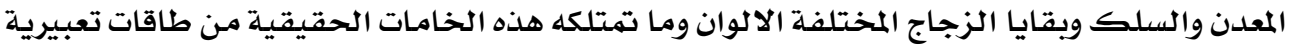

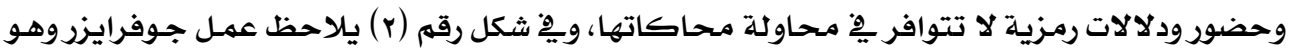

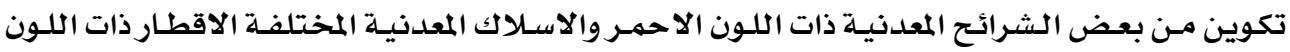

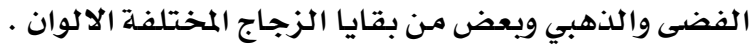

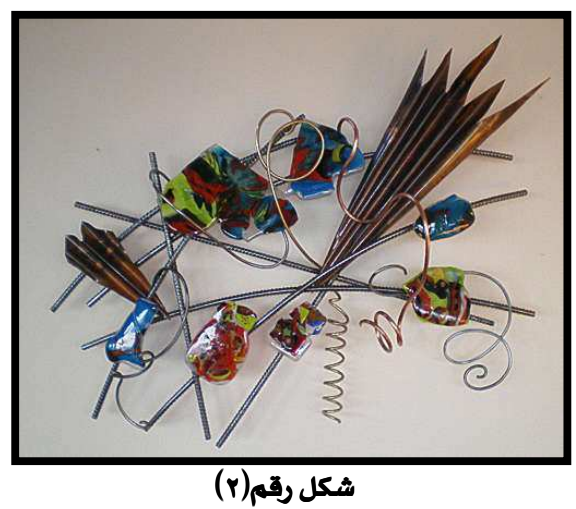

السريالية Surrealism :والتجبيع فى السريالية:

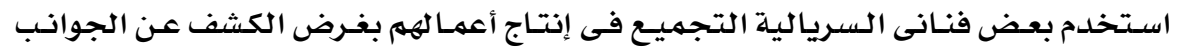

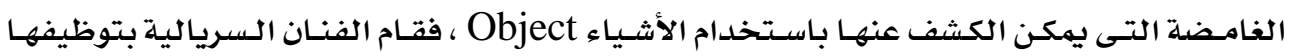

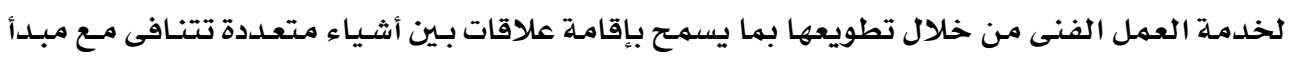

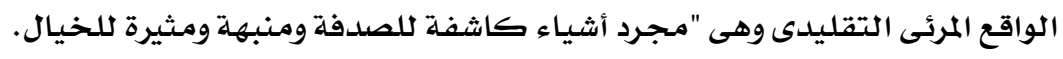

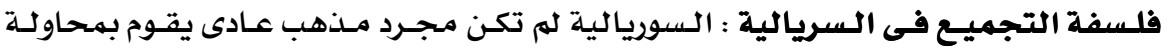

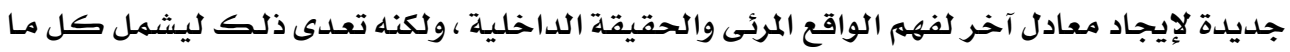

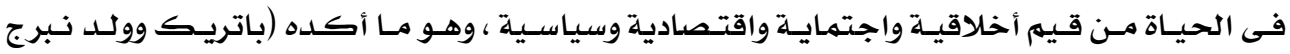

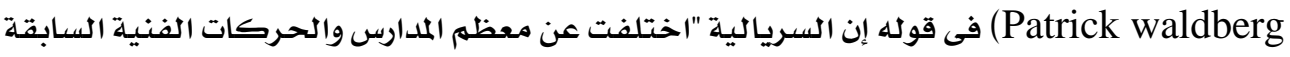

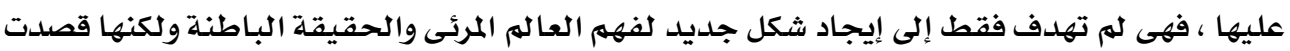

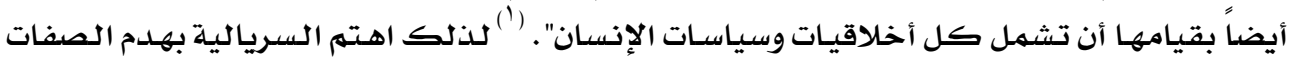

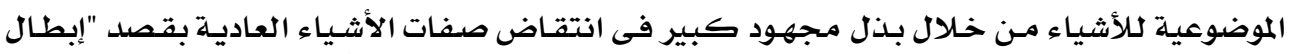

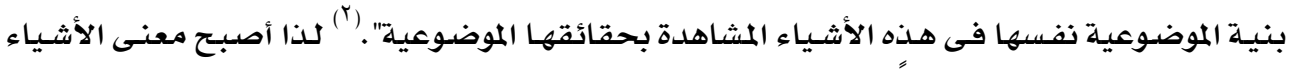

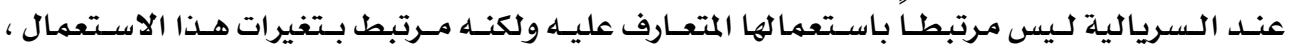

(') Patrich Waldberg 1980 : The intiators of surrcalism, A Merican kibbrary, New York, P. 5. 


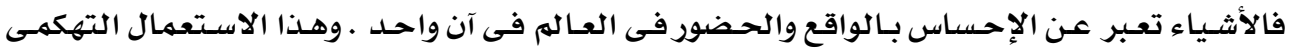

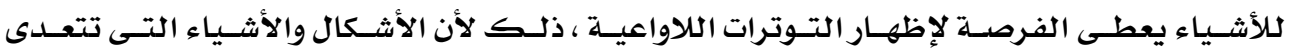

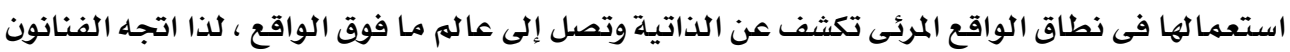

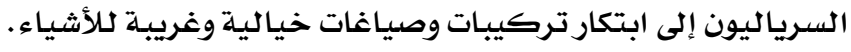
توظيف السريالية لفن التجميع : كان اختيار الأشياء فى السريالية يتتم لمعانيها الشعرية

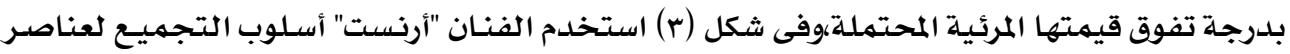

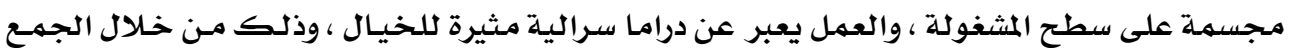

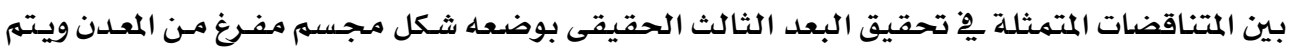

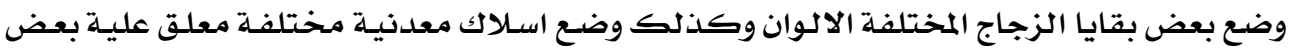

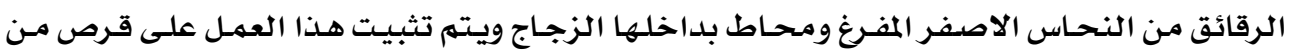

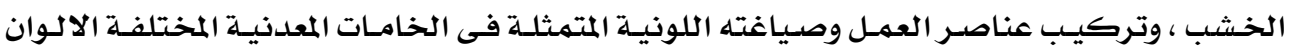

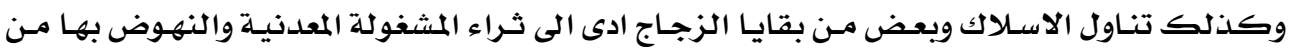

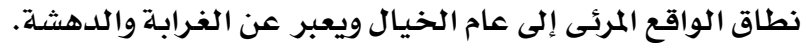

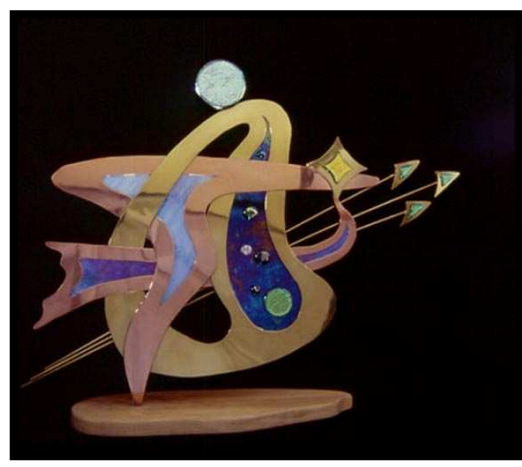

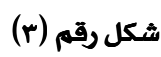

فن البوب :-

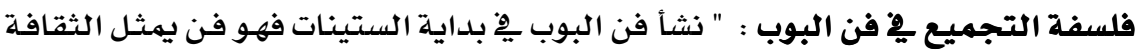

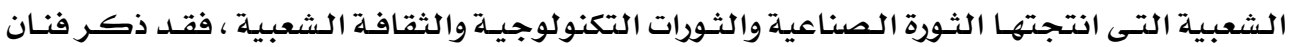

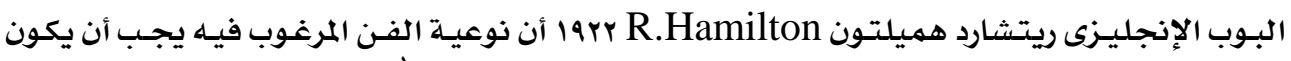

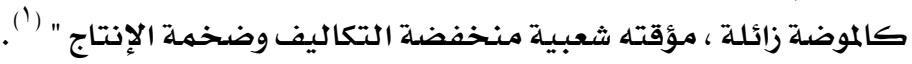

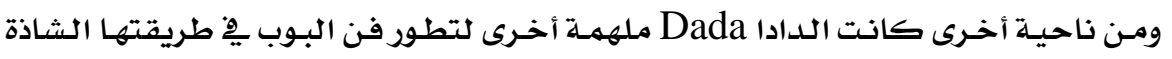
التى جمعت بها الأشياء . فالتوليف والتجميع هما مبدآن شكليان جوهريان ِِّ فن البوب .

(1) Denis Thomas 1981 : Dictionary of fine Arts. Hamlyn, London, New York, p. 139. 


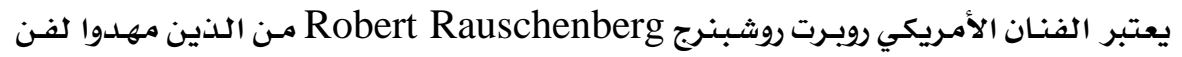

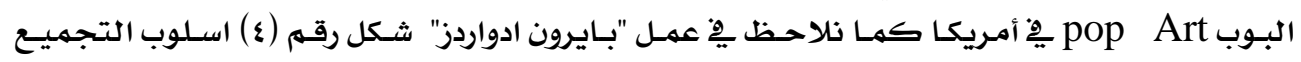

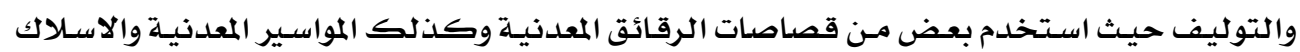

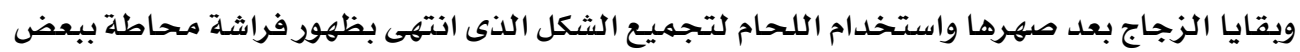

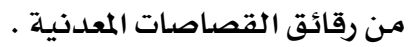

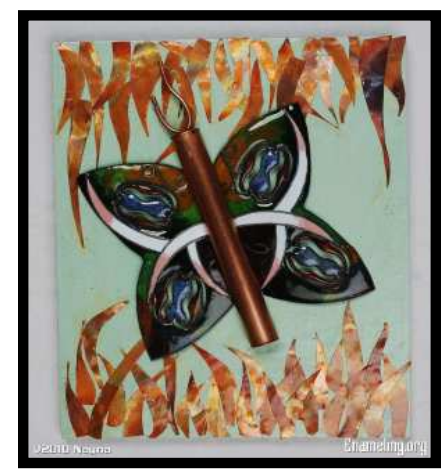

شكل رقم (६)

الواقعية الجديدة : وفلسفة التجميع ِِّ الواقعية الجديدة :

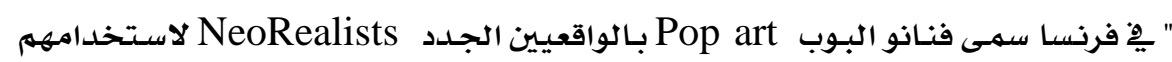

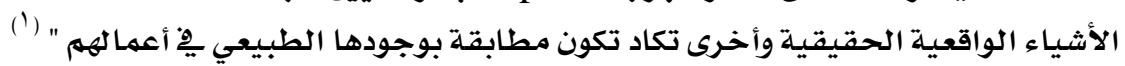

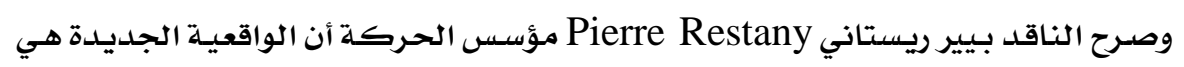

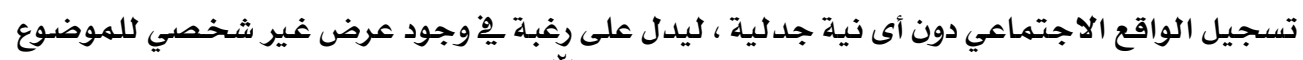

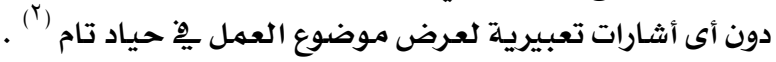

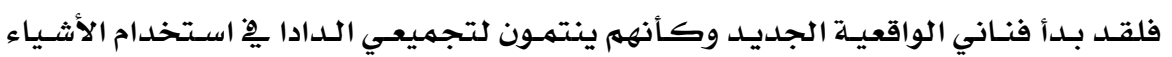

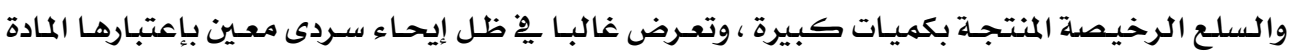
الخام للتجميع · والع الرخين. توظيف الواقعية الجديدة لفن التجميع :-

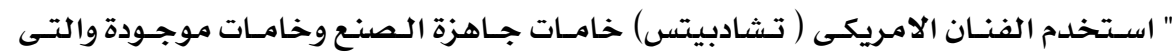

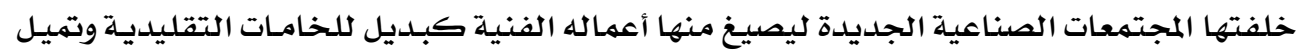

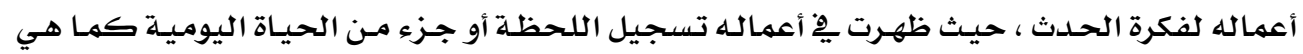

(1) Tillman osteroold 1995: popart taschen, koln, p.115

(2) H.H. Arnasoi 1975 : A history of modern Art painting sculpture. Architecture, thames and Hudson, p. 603. 


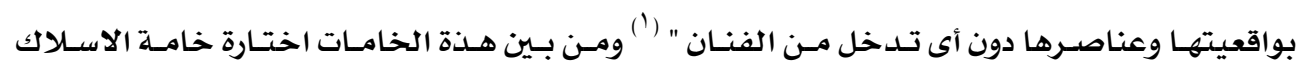
النحاسية لتشكيل دراجة محاط فى اطاراتها بعض من الزجاج ذات اللون الاصفر والازرق مغلفة بـاطار نحاسي كما نلاحظ فى شكل رقم (0) ، ومـن هنا بتجميـع الزجاج والمعدن ادى الى ثراء العمل الفنى .

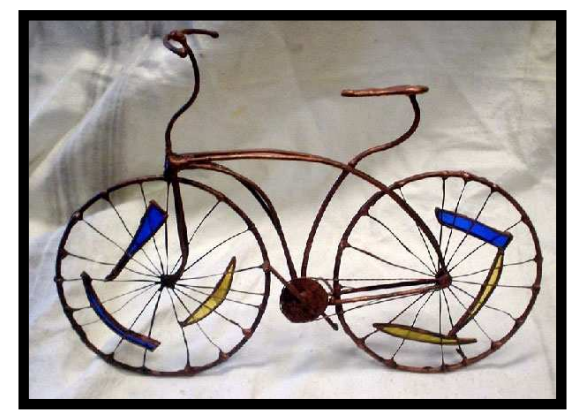

شكل رقم (0)

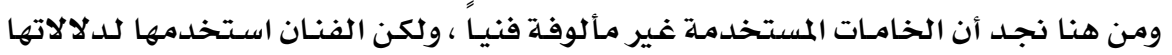

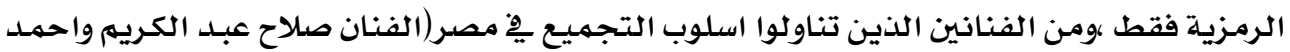

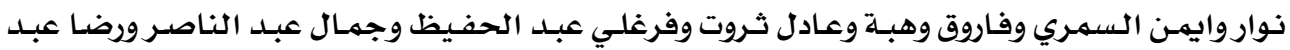

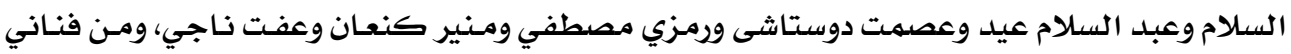

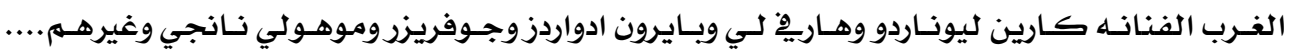

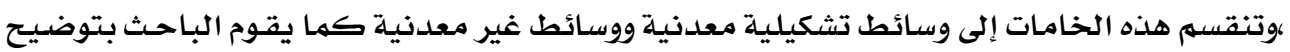

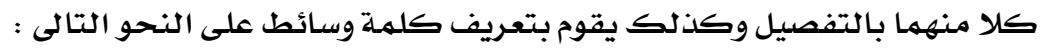

\section{أ ـ الوسائط : Media}

"ورد في المعظم الوسيط ، الوسيط : المتوسط بـين المتخاصـمين والمتوسط بـين المتبـايعين أو

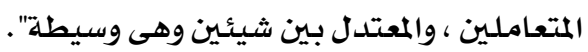

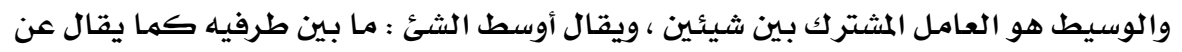

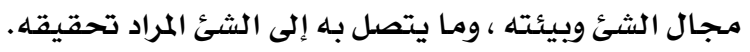

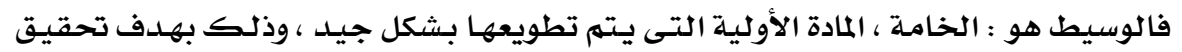

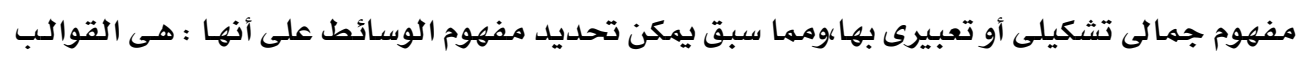

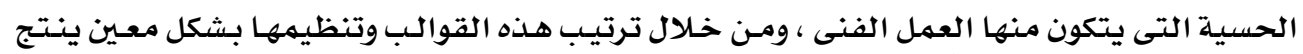

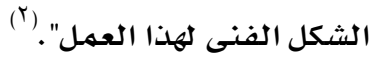

(1) Neville Weston 1968 : kaleidoscope of modern Art Harry London, p. 208.

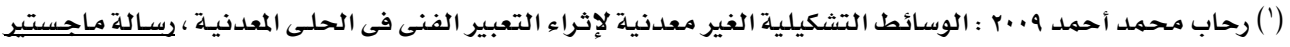

غير منشورة ، كلية التربية الفنية ، جامعة حلوان ، صبr. 


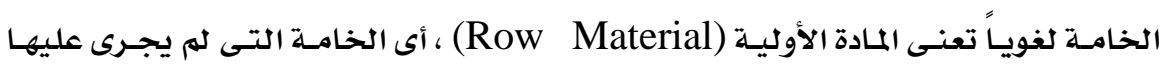

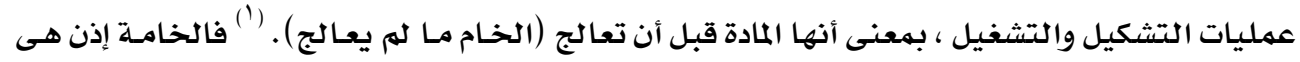

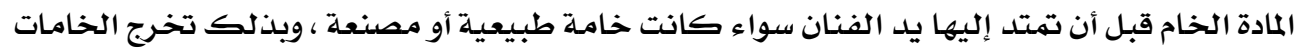

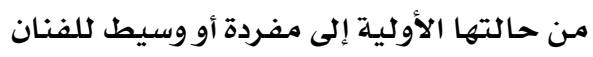

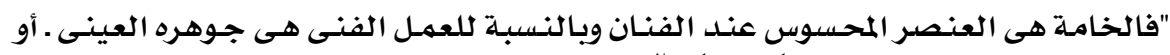

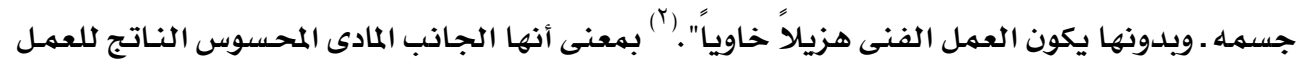
الفني ج

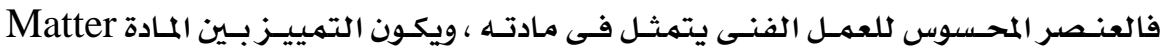

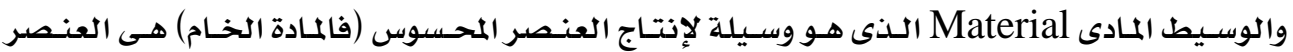

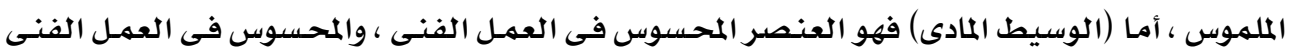

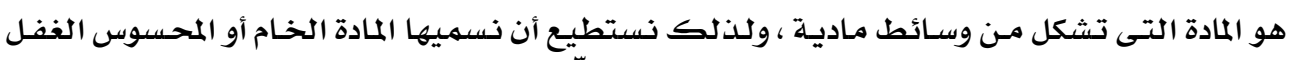
(") كما نلقاه فى الإدراك العادى" (Brute Sensuous)

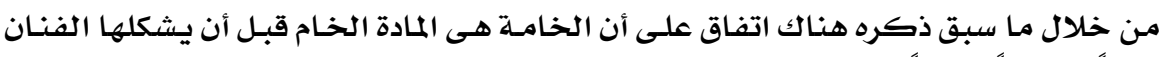

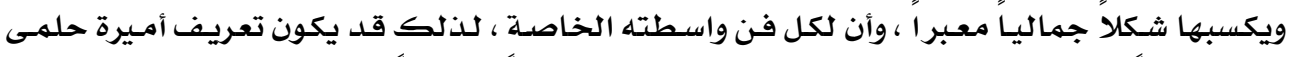

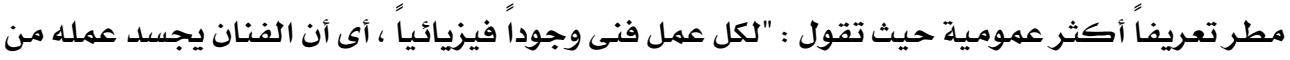

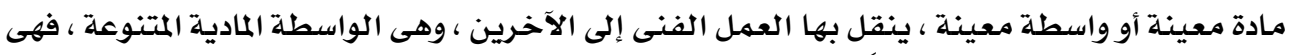

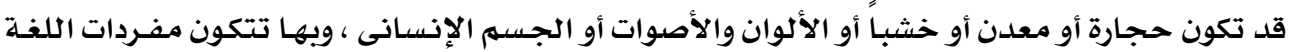

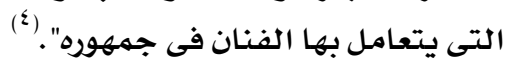

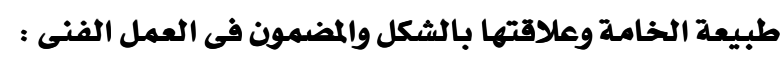

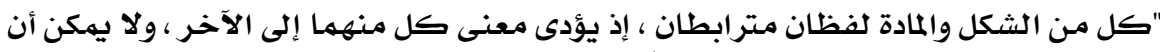

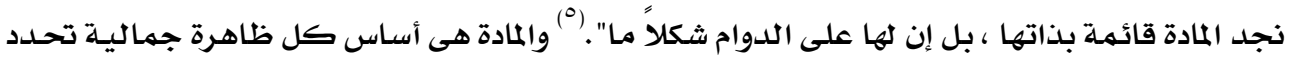

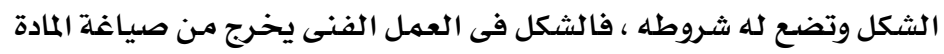

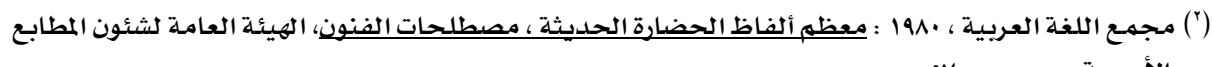

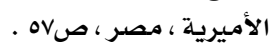

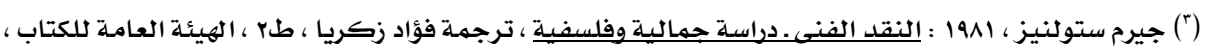

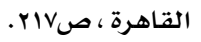

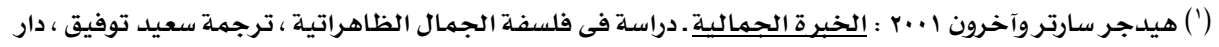

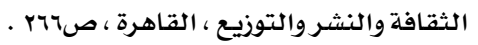

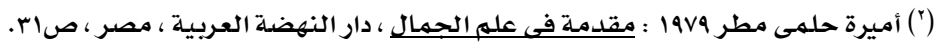

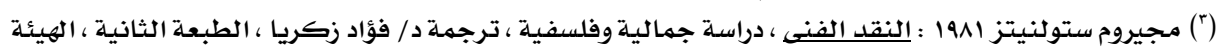

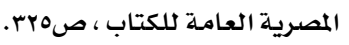




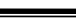

ويعتبر أرنست فيـر "أن الشكل هـو التعبير عـن حالــة المـادة والظـروف الماديـة التى تتميـز

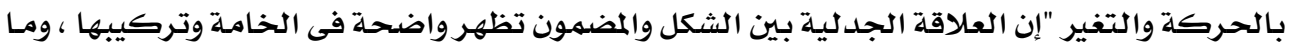

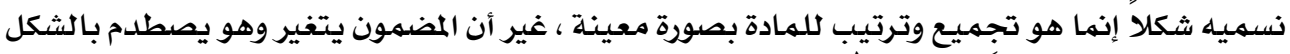

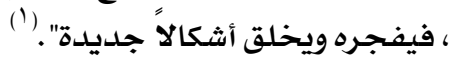

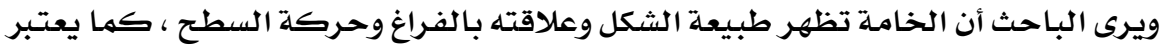

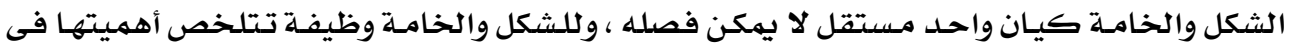
ترتيب عناصر العمل الفنى بصورة من شأنها أن تظهر قيمتها الحسية وانهية والتعبيريـة والجمالية.

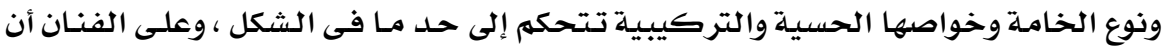

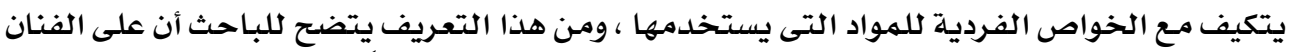

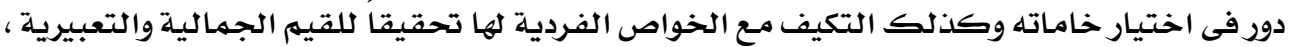

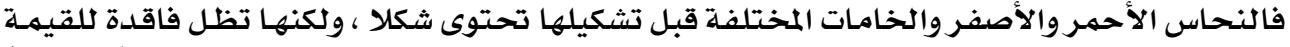

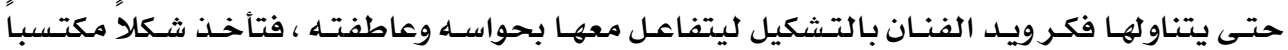

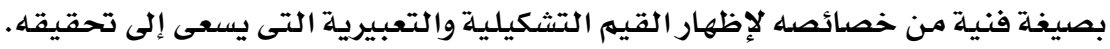

\section{الخامة كأداة تعبير :}

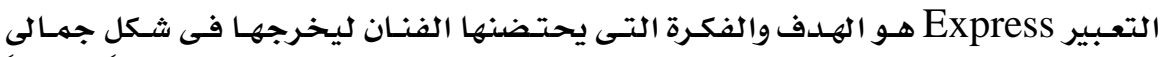

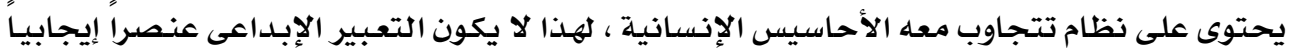

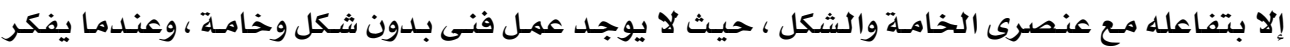

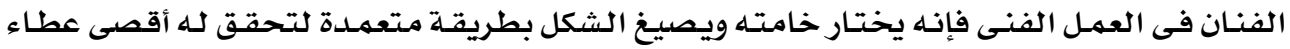

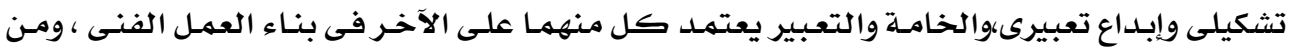

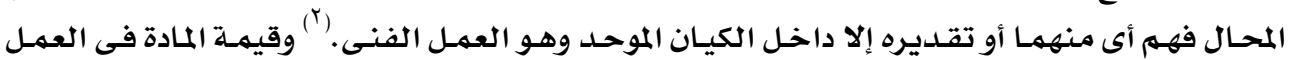

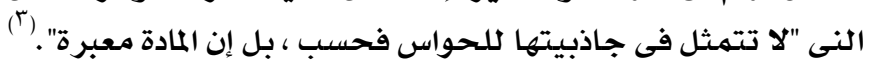

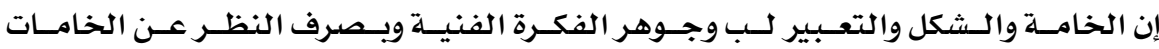

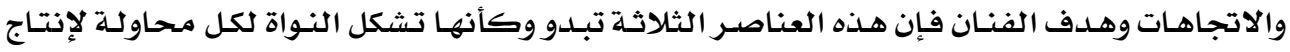

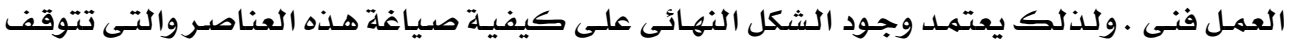

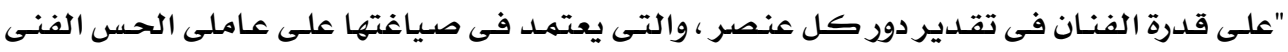

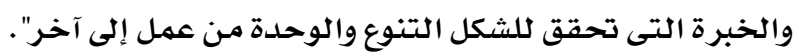

(') أرنست فيشر 1991 : ضرورة الفن ، ترجمة / أسعد حليهم ، الهيئة المصرية العامة لكتاب ، صعا1 .

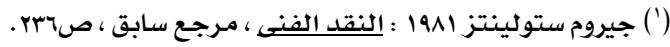

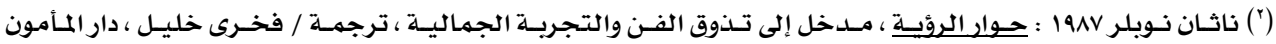


الفنان وعلاقته بالخامة :

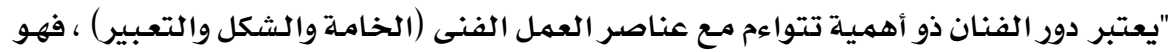

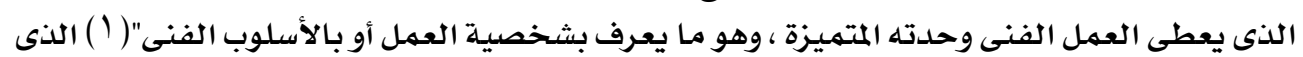

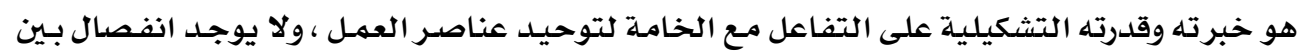

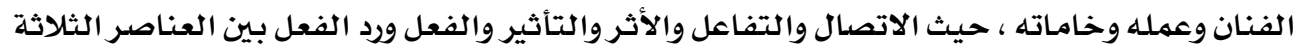
، والتى بتلاحمها تشكل أسلوب الفنان.

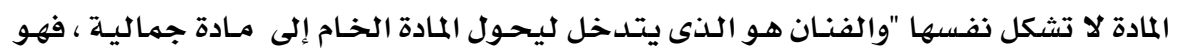

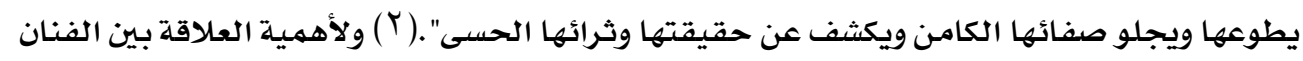

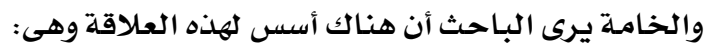
أ ـ القدرة المهارية الإبداعية : وهى ترتبط بشخصية الفنـان وقدرته على تنفيـذ أعمالهه بأسلوب مميـز

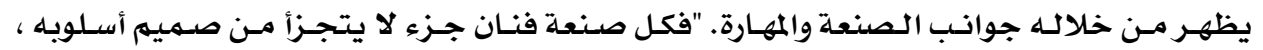

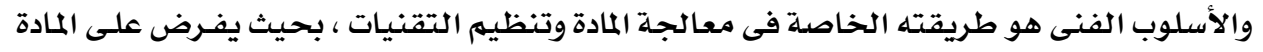

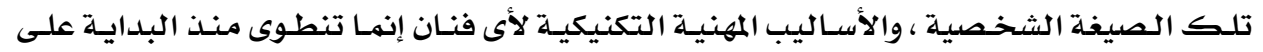

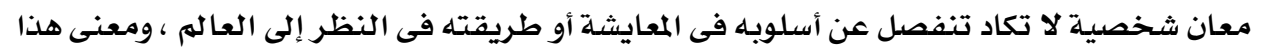

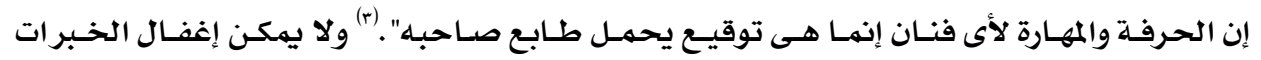

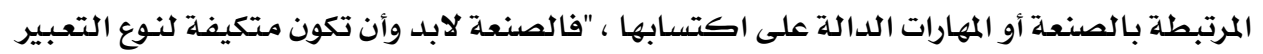

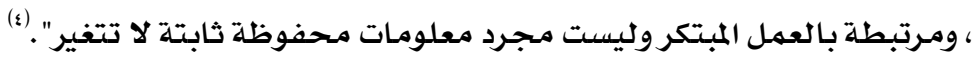

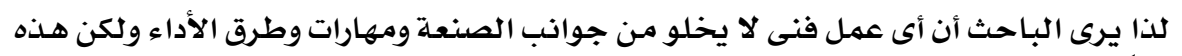

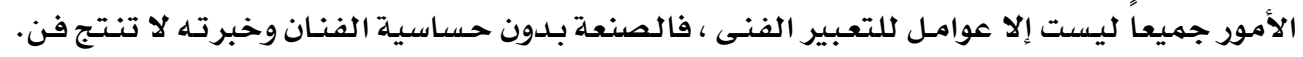

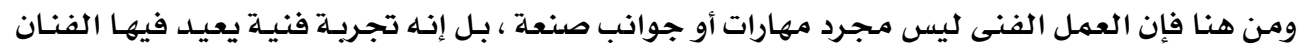

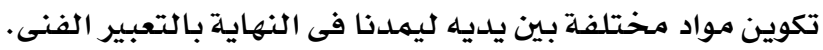

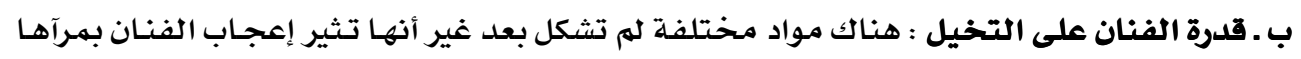

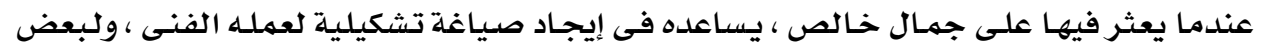

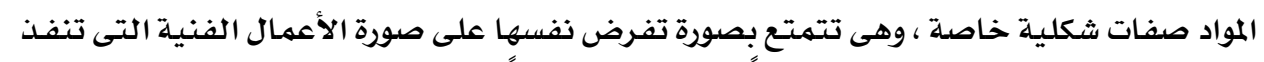

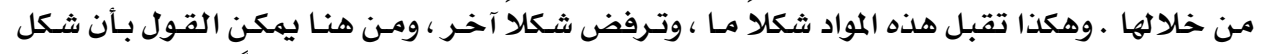

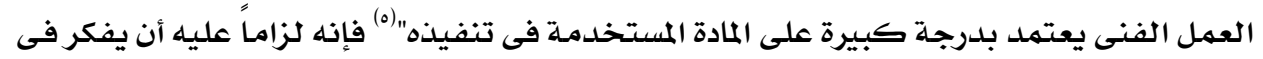

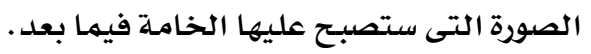

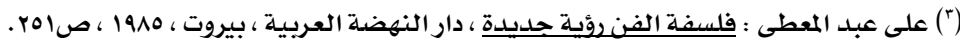

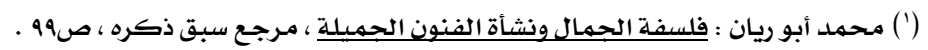

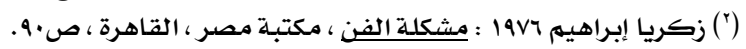

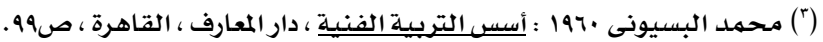

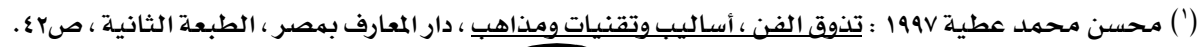




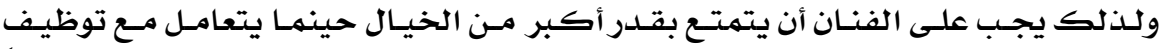

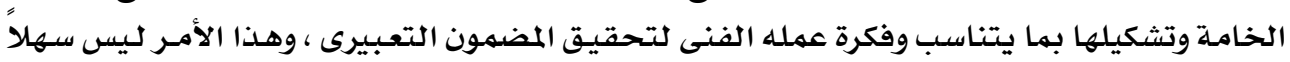

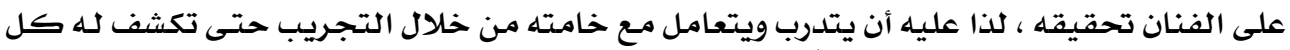

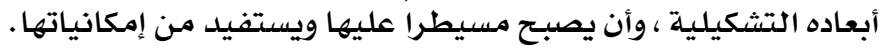

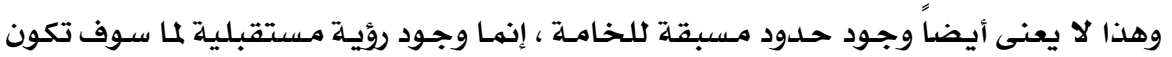

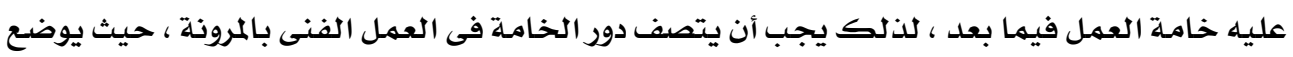

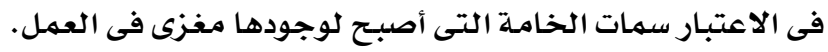

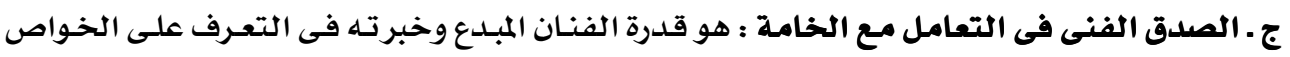

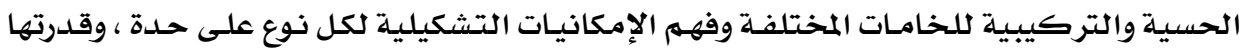

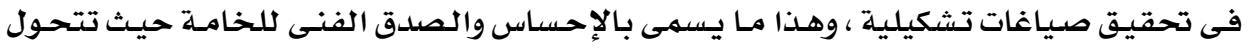

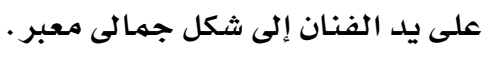

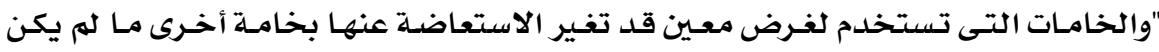

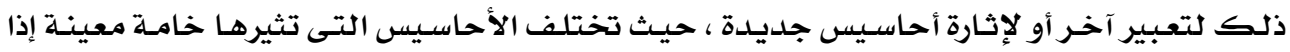

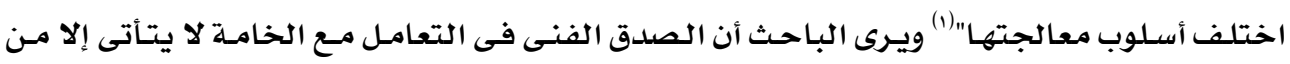

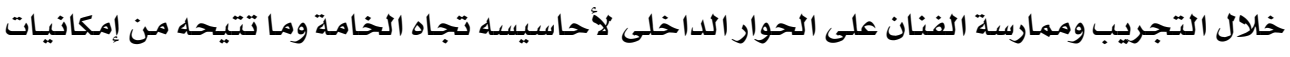

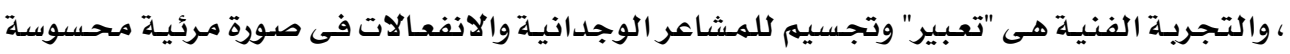

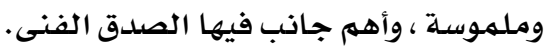

r- r التقنية كوسيط تشكيلى :

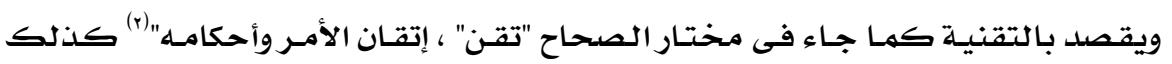

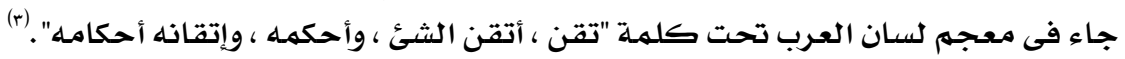

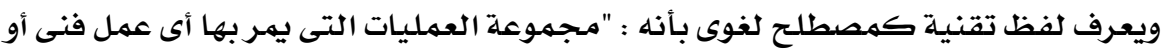

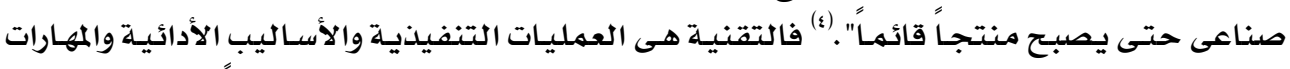

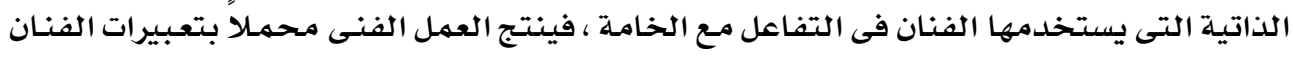
الداخلية التى قد سبق وأن تصورها.

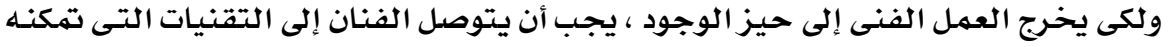

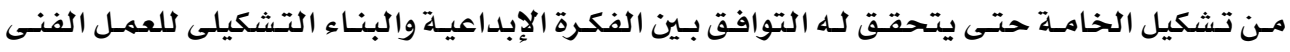

(') عبد الفتاح رياض 1990 : التكوين في الفنون التشكيلية ، دار النهضة العربية ، القاهرة ، صrrr.

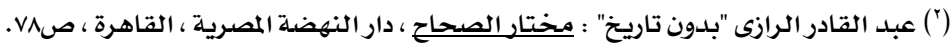

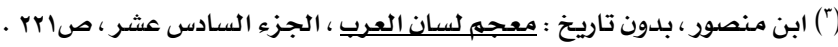

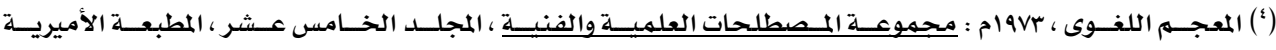


"فالنشاط الإبداعى للفنان يتطلب حرية الفكر والأداء واستخدامـه لتقنيات متعـددة تمهد لـه الطريقق

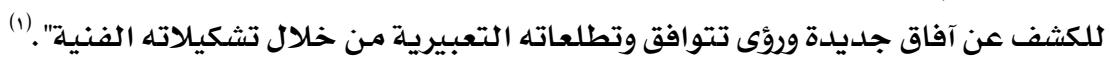
وتعد التقنية عملية مركبة للفنان تبدأ منذ اختياره للخامسة التى يتفاعل معها ثم القيام

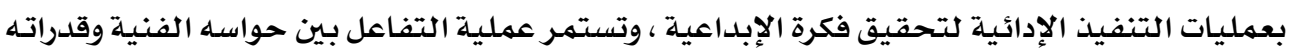

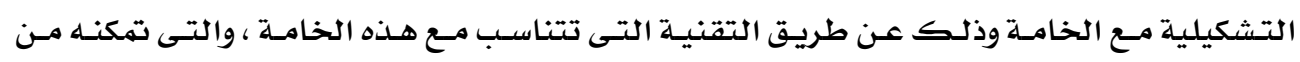

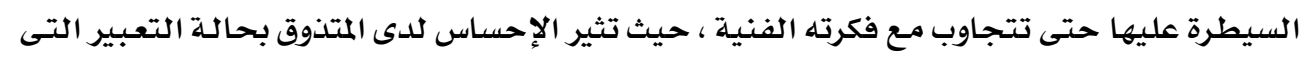
تظهر فى الشكل النهائى للعمل الفنى.

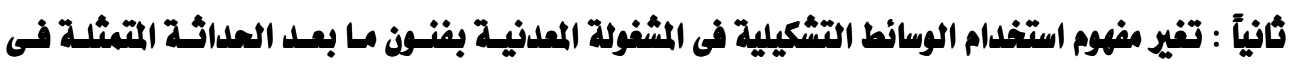

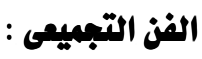

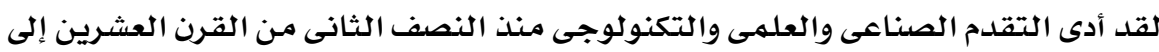

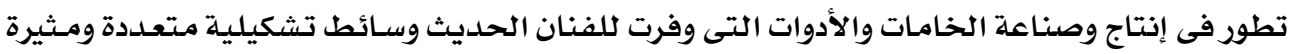
لكلإبداع الفنى. تورى إنتاج

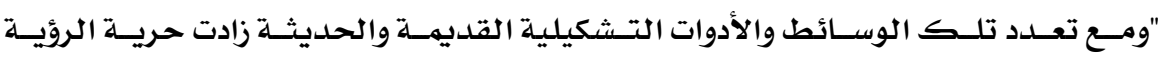

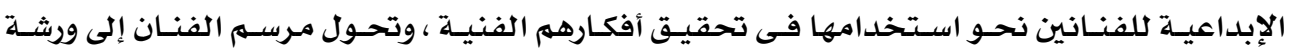

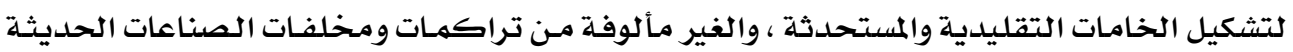

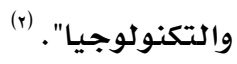

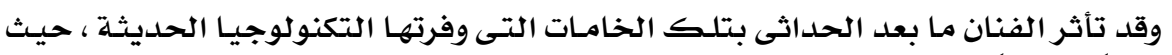

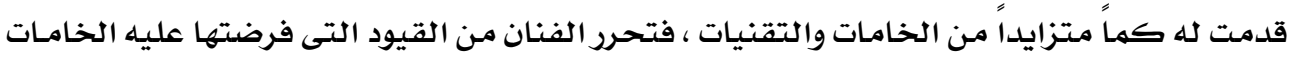

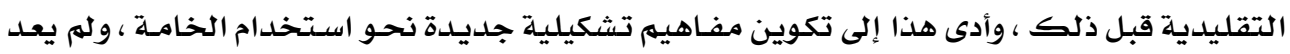

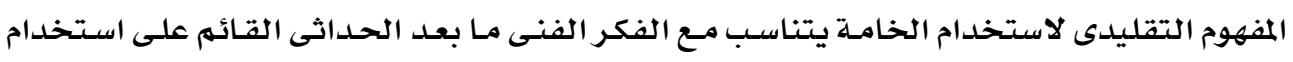

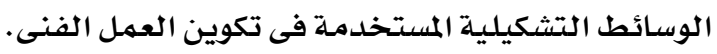

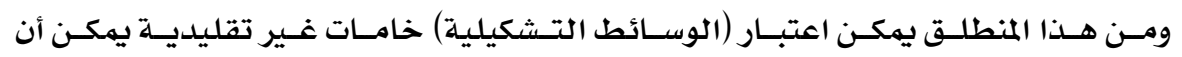

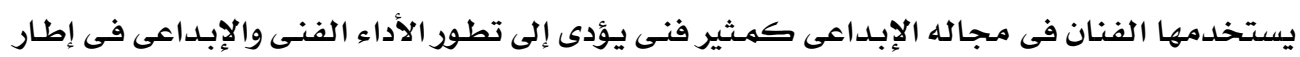

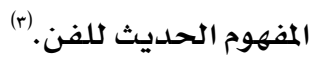

(") أحمد حافظ حسن $19 v V$ : التشكيل بالسلك ، معرض فني منظر،قاعة حورس،كلية التربية الفنية، صا . $\left(^{2}\right)$ Ray Faulkner, Eziegfeld, 1969 : "Art Today" Halt Rinchart \& Winston, Inc., New York, P. 469.

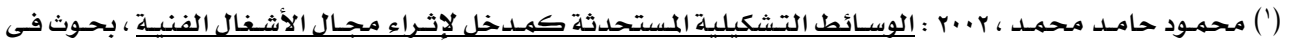
التربية الفنية والفنون ، المجلد السادس ، العدد السادس ، نوفمبر ، كلية التربية الفنية ، جامعة حلوان ، صrr. 
أ ـ مفهوم الوسائط التشكيلية فى المشغولة المعدنية بفنون ما بعد الحداثة :

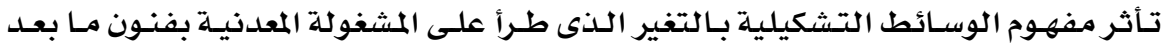

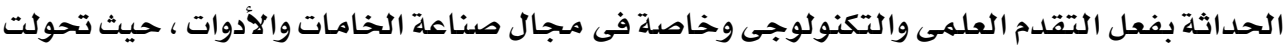

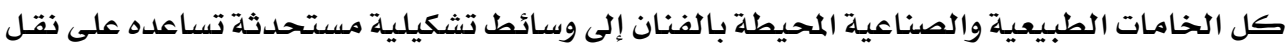
أفكاره وترجمة مشاعره لكلآخرين. وعلى ذلك يمكن تعريف (مفهوم الوسـائط التشكيلية) المستخدمة فى المشغولات المعدنيـة. بفنون ما بعد الحداثة على النحو التالى :

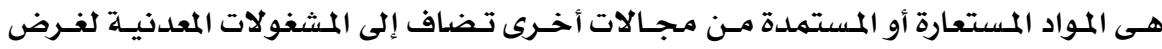

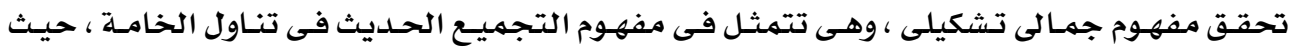

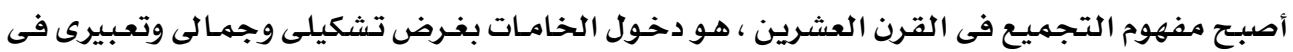

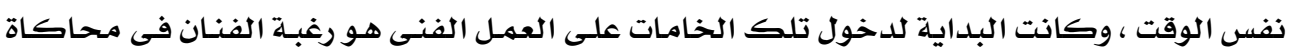

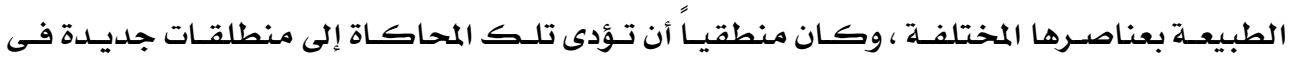

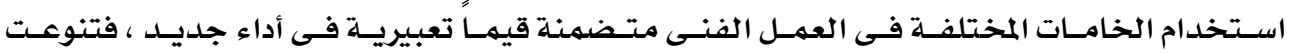
وتعددت الخامات. (1) وانطلاقًاً مـن وعى المصمممين بـتغير المفـاهيم الجماليـة للخامسة ، حيـث أصبـحت تمثل بعـداً

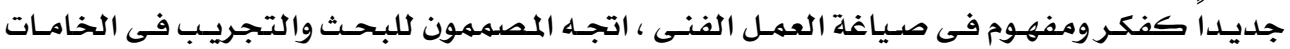

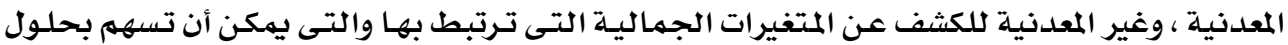

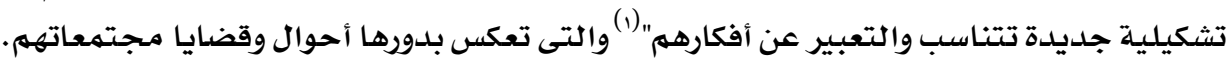
لذلك أخذ الفنان فيما بعد الحداثى يبحث عن (الوسائط التشكيلية) التى تتناسب لإثراء

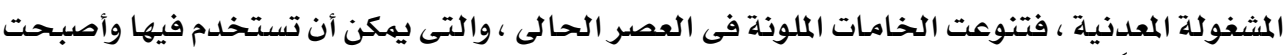

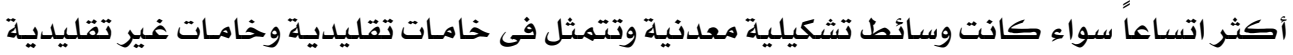

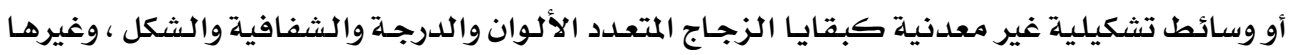

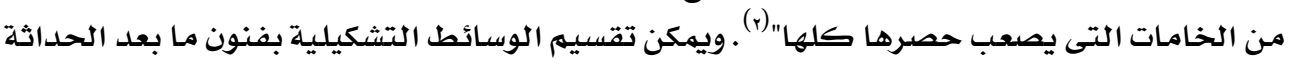

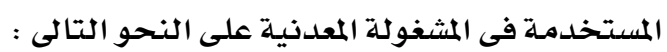

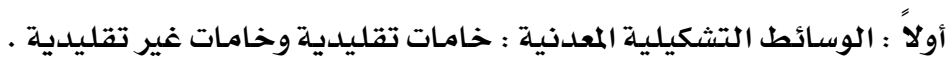

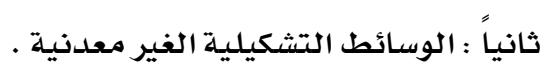

(1) Carlson Lauire, 2001: Fiber Arts, Vol 26. No 5 Lark Books . USA, P. 42.

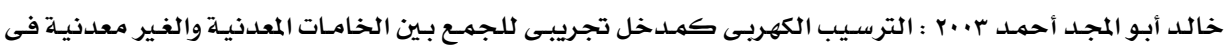

صياغات مستحدثة ، رسالة دكتوراه ، غير منشورة ، كلية التربية الفنية ، جامعة حلوان ، صعى . 2

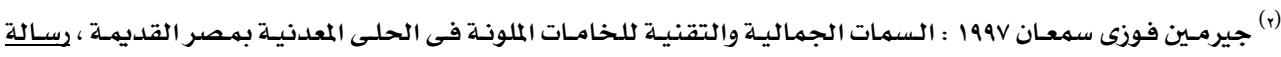
ماحستير غير منشورة 


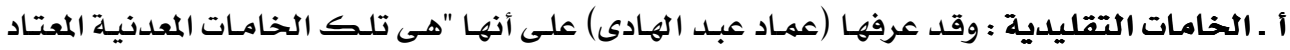

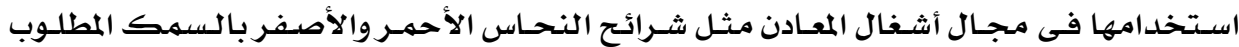

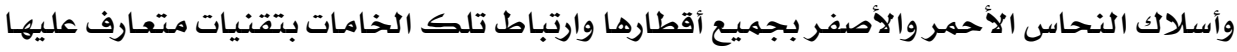

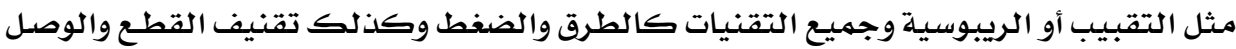

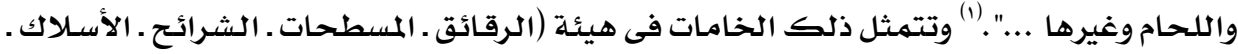

$$
\text { الشبك ـ المواسير). }
$$

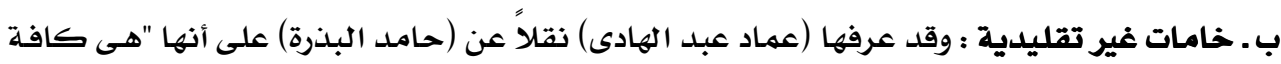

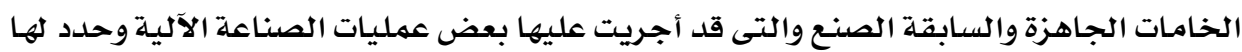

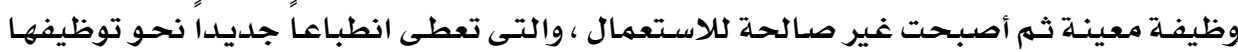

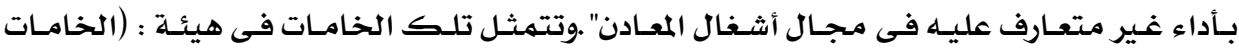

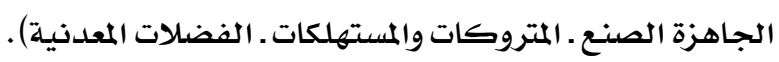

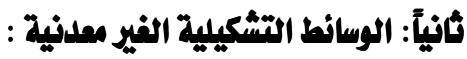

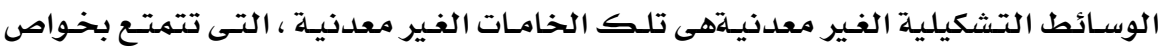

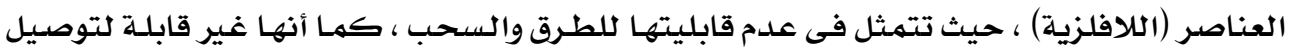

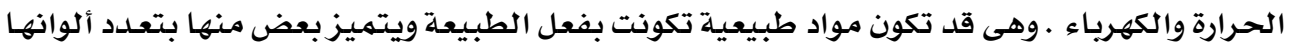

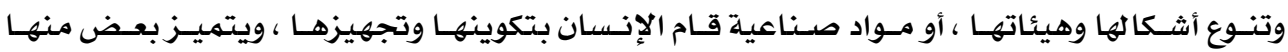

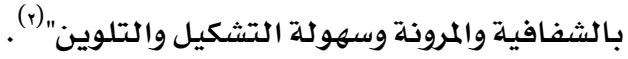
وليس معنى هـذا أن المقصود (بالوسـائط التشكيلية الغير معدنيـة) أنها خامـات (لافلزيـة) ،

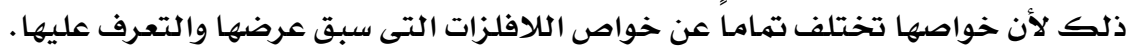

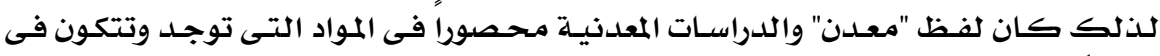

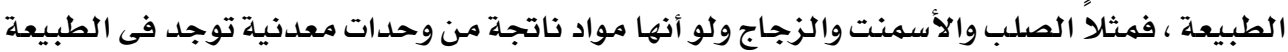

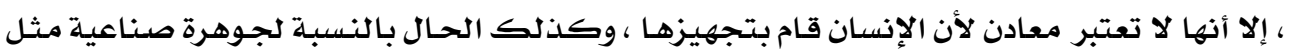

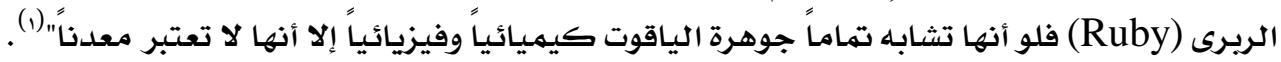

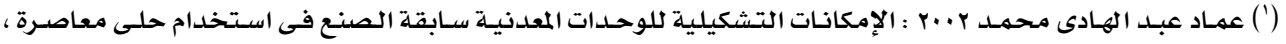

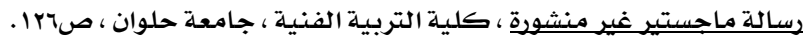

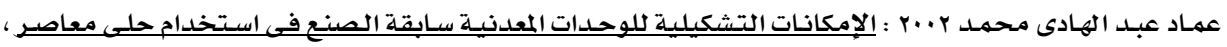




\section{من الدراسة كانت النتيجة:}

- من استخدام أسلوب المزاوجة بين الخامات المعدنية والوسائط التشكيلية المتمثلة ِِِ بقايا الزجاج

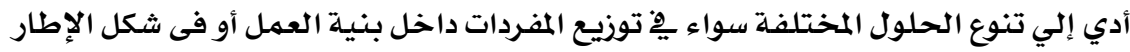

$$
\text { - ولخذك يوصى الباحث : النمهل الفني ككل وذلك مها عرض. }
$$

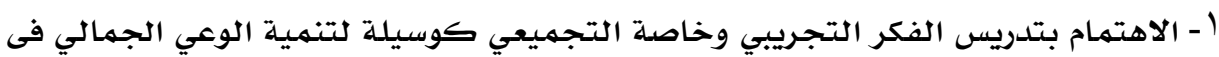

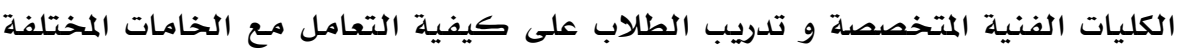

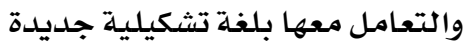

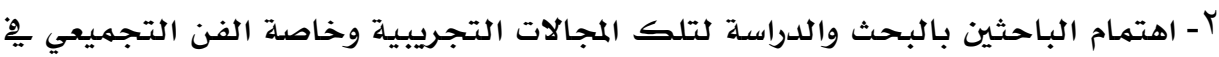

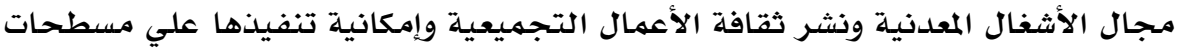
مختلفة بخامات مناسبة.

1- محمد عز الدين حلمى \&19V1 :علم المعادن،مكتبـة الأنجلو المصرية، طب،القاهرة

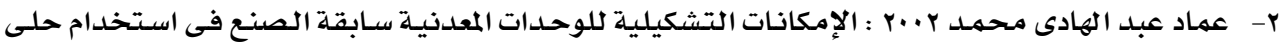
معاصرة،رسالة ماجستير غير منشورة،كلية التربية الفنية،جامعة حلوان

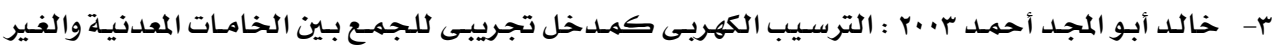
معدنية فى صياغات مستحدثة ، رسالة دكتوراه ، غير منشورة ، كلية التربية الفنية ، جامعة حلوان

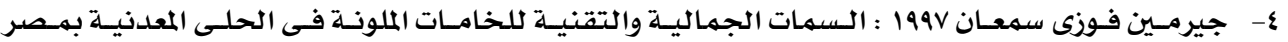
القديمسة ، رسالة ماجستير غير منشورة

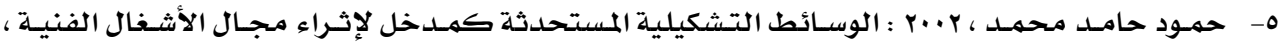
بحـوث فـى التربيـة الفنيـة والفنـون ، المجلــد السـادس ، العـدد السـادس ، نـوفمبر ، كليـة التربيـة الفنيـة ، جامعة حلوان 7- عبد الفتاح رياض 1990 : التكوين فى الفنون التشكيلية ، دار النهضة العربية ، القاهرة V- عبد القادر الرازى "بلدون تاريخ":مختار الصحاح،دار النهضدة المصرية ،القاهرة ^- ابن منصور،بلدون تاريخ:معجم لسـان العرب،الجزء السـادس عشر

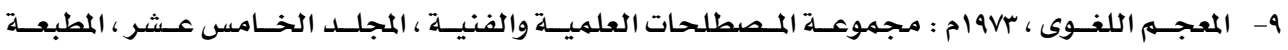
الأميريـة القاهرة • جامعة حلوان،

11 - محسن محمد عطية 1997 : تذوق الفن،أساليب وتقنيات ومـذاهب، دار المعارف بمصر،الطبعة الثانية r ا - زكريا إبراهيم 19V7 : مشكلة الفن ،مكتبة مصر ، القاهرة 
با - محمد البسيونى •197 :أسس التربية الفنية،دار المعارف، القاهرة

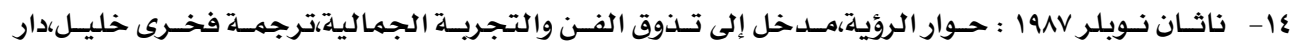
المأمون للترجمـة.

10 - على عبد المعطى : فلسفة الفن رؤيسة جلديدة،دار النهضة العربية،بيروت ، 1910 17 - أرنست فيشر 1991 : ضرورة الفن ترجمة أسعد حليه،الهيئة المصرية العامة لكتاب

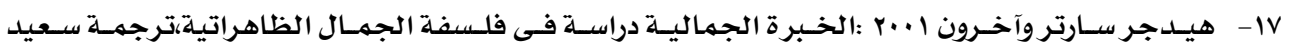
توفيق،دار الثقافة والنشر والتوزيـع،القاهرة. 11- أميرة حلمى مطر 19V9 :مقدمـة فى علم الجمال،دار النهضة العربية، مصر

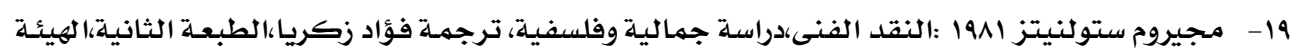
المصريـة العامـة للكتاب

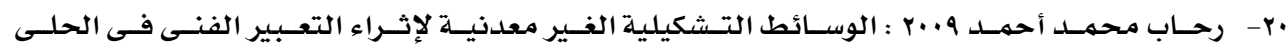
المعدنيلة،رسالة ماجستير غير منشورة،كلية التربية الفنية،جامامعة حلوان

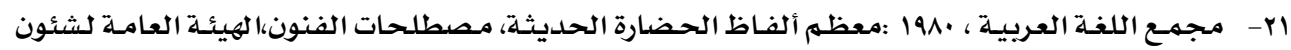
المطابع الأميرية،مصر.

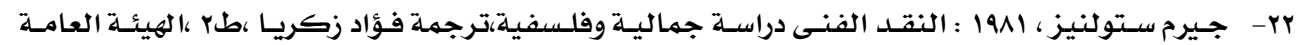
للكتاب،القاهرة

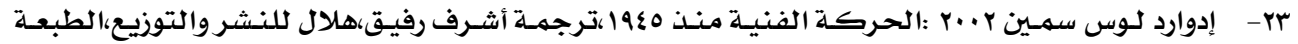
الأولى،القاهرة.

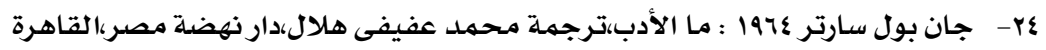

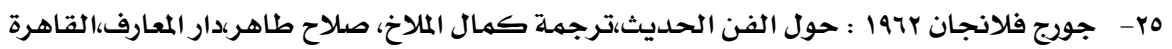

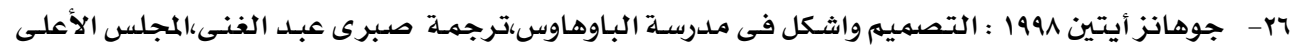
للثقافة،القاهرة

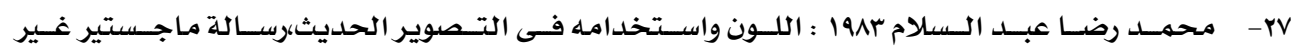
منشورة،كلية الفنون الجميلة،جامعة حلوان

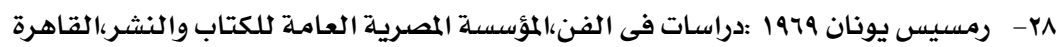

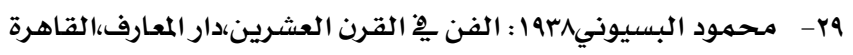

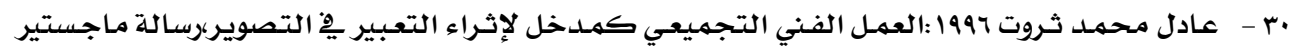
غير منشورة ،كلية التربية الفنية جامعـة حلوان 


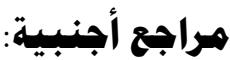

31- Carlson Lauire, 2001: Fiber Arts, Vol 26. No 5 Lark Books . USA

32- Ray Faulkner, Eziegfeld, 1969 : "Art Today" Halt Rinchart \& Winston, Inc., New York,

33- (1) Neville Weston 1968 : kaleidoscope of modern Art Harry London

34-Tillman osteroold 1995: popart taschen, koln,

35-H.H. Arnasoi 1975 : A history of modern Art painting sculpture. Architecture, thames and Hudson

36-Denis Thomas 1981 : Dictionary of fine Arts. Hamlyn, London, New York

37-Patrich Waldberg 1980 : The intiators of surrcalism, A Merican kibbrary, New York

38-Duane and Sarah Preble : 1985 Art forms Harper and Row publishers new York

39-Robert Atkins 1990 : Art Speak" Abbeville Ruess, New York

40-Richard leslie : 1997, pop art anew Generation of style todri, new York

41-Modern Art Collins Glasgow, London Edward Lucie - Smith: 1987, Sculpture Since. 1945,

42-H.H. Arnasoi : 1975 , A history of Modern Art Painting . Sculpture. Architectur, Thames and Hudson 